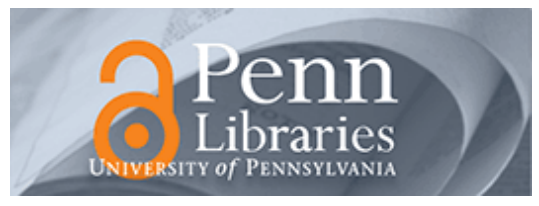

University of Pennsylvania

ScholarlyCommons

Marketing Papers

Wharton Faculty Research

2-2018

\title{
A Model of Product Design and Information Disclosure Investments
}

Panos M. Markopoulos

Kartik Hosanagar

University of Pennsylvania

Follow this and additional works at: https://repository.upenn.edu/marketing_papers

Part of the Advertising and Promotion Management Commons, Business Administration, Management, and Operations Commons, Business Analytics Commons, Business and Corporate Communications Commons, Business Intelligence Commons, Marketing Commons, Operations and Supply Chain Management Commons, and the Organizational Behavior and Theory Commons

\section{Recommended Citation}

Markopoulos, P. M., \& Hosanagar, K. (2018). A Model of Product Design and Information Disclosure Investments. Management Science, 64 (2), 739-759. http://dx.doi.org/10.1287/mnsc.2016.2634

This paper is posted at ScholarlyCommons. https://repository.upenn.edu/marketing_papers/321

For more information, please contact repository@pobox.upenn.edu. 


\title{
A Model of Product Design and Information Disclosure Investments
}

\begin{abstract}
New technologies such as product simulators and virtual reality now allow firms to provide realistic product usage experiences and reduce buyer uncertainty about product quality. We argue that today's firms should view product design and investments to reduce buyer uncertainty as an integrated process, which is in turn influenced by how much information buyers can obtain from third-party infomediaries. We introduce a game-theoretic model of a competitive market where both quality production and quality disclosure are endogenous decisions, affected by information made available by third parties. We show that quality investment under uncertainty never exceeds the level of quality investment under perfect information. Furthermore, we show that information availability by third parties allows firms to free ride, and it especially favors lower quality firms, who can reduce their information disclosure investments more so than higher-quality firms. Finally, we show that the intuitive argument that firms must improve their product quality when overall information availability in the market improves does not always hold. Instead, improved information availability may enable firms to reduce their quality in some situations.
\end{abstract}

\section{Keywords}

buyer uncertainty, information disclosure, product quality, infomediaries

\section{Disciplines}

Advertising and Promotion Management | Business | Business Administration, Management, and Operations | Business Analytics | Business and Corporate Communications | Business Intelligence | Marketing | Operations and Supply Chain Management | Organizational Behavior and Theory 


\title{
A Model of Product Design and Information Disclosure Investments
}

\author{
Panos M. Markopoulos \\ Business and Public Administration University of Cyprus, P.O. Box 20537, Nicosia, CY-1678, Cyprus, \\ markopoulos.panos@ucy.ac.cy
}

Kartik Hosanagar

Wharton School, University of Pennsylvania, 3730 Walnut Street, Philadelphia, PA 19104, USA, kartikh@wharton.upenn.edu

\begin{abstract}
New technologies such as product simulators and virtual reality now allow firms to provide realistic product usage experiences and reduce buyer uncertainty about product quality. We argue that today's firms should view product design and investments to reduce buyer uncertainty as an integrated process, which is in turn influenced by how much information buyers can obtain from third-party infomediaries. We introduce a gametheoretic model of a competitive market where both quality production and quality disclosure are endogenous decisions, affected by information made available by third parties. We show that quality investment under uncertainty never exceeds the level of quality investment under perfect information. Further, we show that information availability by third parties allows firms to free ride, and especially favors lower quality firms, who can reduce their information disclosure investments more so than higher quality firms. Finally, we show that the intuitive argument that firms must improve their product quality when overall information availability in the market improves does not always hold, and it may in some situations enable them to reduce their quality instead.
\end{abstract}

Key words: Buyer uncertainty, information disclosure, product quality, infomediaries

\section{Introduction}

A major activity in markets is the transfer of product information by firms and third-party intermediaries to buyers. New technology allows firms to improve buyer knowledge about their products. Sellers can showcase video instructions of product use, as Apple does for its laptops, and can employ technology that allows buyers to simulate the experience of owning the actual product, as gaming company Electronic Arts does with its playable demos. Emerging technologies like Virtual Reality further allow firms to give consumers realistic product usage experiences prior to purchase.

Technology has also made it easy for consumers to acquire product information from independent third-parties (Montgomery et al. 2004). These infomediaries offer expert product evaluations (Chen and Xie 2005), aggregate consumer reviews (Koh et al. 2010), or educate consumers about the product category in general. Many retailers, such as Amazon and JEGR Electronics, also offer consumer reviews and expert product evaluations. The social commerce trend, currently exemplified by firms such as Facebook and Pinterest, also allows consumers to share product information and assessments with one another. The consequences of this "ambient information" made available by 
third parties is that consumers have an important alternative source of product information and need not rely exclusively on information provided by the manufacturers.

While product videos, product simulators, playable demos and other similar technologies can make it easier for firms to provide product quality information to consumers, they can be expensive. For example, playable game demos for PC games are non-trivial investments (Crossley 2010) and Electronic Arts has discussed the possibility of charging $\$ 10-\$ 15$ per comprehensive game demo (Martin 2010), in order to justify the extra development costs. In fact, we collected data on 2196 PC games released between 1996 and 2005 and found that only 55\% invested in creating a playable demo. Firms have to determine when it is worthwhile to invest in product information disclosure and, in particular, assess how ambient information availability affects these decisions. Further, given the growing importance of information investments, these investments should be viewed as an integral part of the product design process. Firms have to determine how much to invest in quality given the subsequent cost of informing customers about these quality attributes.

Consider two printer manufacturers who have recently released different printer models, one of which is high-end, while the other is a budget model. When trying to determine whether to invest in information disclosure, the firms face different choices and trade-offs due to their difference in quality. Consider further that a popular intermediary has just released a thorough and fair quality review on the two models. Should the firms adjust their plans for information disclosure investments, as a result? If so, should the adjustment be different for the two firms? Should the adjustment account for what the other firm is doing?

The key managerial questions in this paper are tied to quality selection and disclosure in the backdrop of alternative product information sources - such as infomediaries - who offer information that can largely substitute the type of information traditionally provided by sellers ${ }^{1}$. First, we ask how firms should invest in informing consumers and, in particular, how product quality influences this decision. Second, we ask how firms should factor in the cost of future information disclosure when choosing product quality levels. Finally, we ask how ambient information from external sources of product information affects the answers to the above questions.

To answer these questions, we present what is to the best of our knowledge the first model of a competitive market where both quality production and quality disclosure are endogenous decisions, affected by information made available by third parties. The model incorporates all the

\footnotetext{
${ }^{1}$ For example, a photographer who needs detailed information about the sharpness of a certain Nikon camera lens can visit Nikons website, or she can visit DxO Labs (dxomark.com), which puts cameras and lenses through standardized tests and often provides more information on Nikon lenses, than Nikon does. Similarly, a consumer who wants to obtain quality information about a Samsung mobile phone can visit Samsung's own website which includes detailed photos from 5-6 different angles. Alternatively, he can visit phonearena.com, which also includes 3D product views. In these and uncountable other examples, sellers and third parties offer quality information that is largely substitutable.
} 


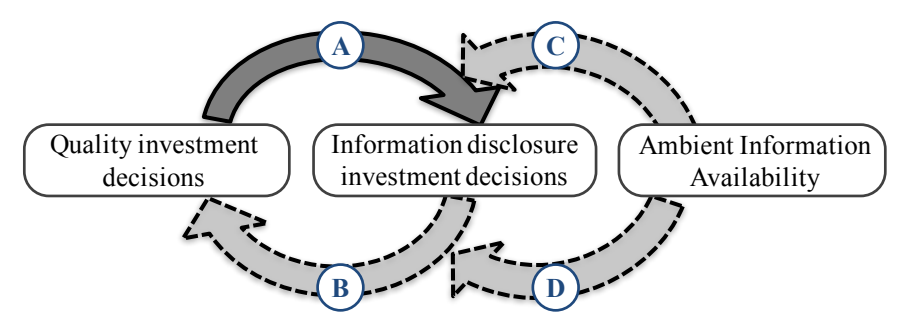

Figure 1 Key interactions considered by our model.

four interactions shown in Figure 1, namely the impact of quality production on disclosure, the impact of future disclosure costs on quality production and the impact of ambient information in the market on both these interactions. We first show that the ex-ante probability of quality disclosure increases smoothly with equilibrium quality. Building on this simple result, we show that firms should view product quality investments and information disclosure investments as an integrated process, and that doing so results in lower quality investments by firms. Further, we show that information availability by third parties allows firms to free ride, and especially favors lower quality firms, who can reduce their information disclosure investments more so than higher quality firms. Finally, we show that information made available by third parties may not always lead firms to improve their quality, and it may actually enable them to reduce their quality instead.

\section{Related Literature}

Much of the current research on product information traces back to the work of Grossman, Milgrom, and Hart (Grossman and Hart 1980; Grossman 1981; Milgrom 1981) and the "unraveling mechanism". The mechanism explains that high quality sellers first report their product quality in order to separate themselves from the group of sellers with unknown quality. That leaves another set of sellers as the highest quality sellers in the group that has not reported yet, giving them the incentive to report their quality in turn, and so on, until all but the lowest quality sellers have provided quality information. Grossman (1981) showed that a similar argument applies even to monopolists who will want to report all but the lowest possible product quality. Grossman \& Hart argue that "the buyers need not be particularly sophisticated or have repeated experience with the seller. [...] The buyer must just use the simple logic that the seller tries to be as optimistic as possible about his product subject to the constraint that he not lie" (Grossman and Hart 1980).

Jovanovic (1982) and Shavell (1994) studied how sellers inform consumers about their quality, when disclosure is costly. They used the unraveling mechanism to show that sellers will invest in disclosure only above a quality threshold that depends on the investment cost. Empirical support for the positive impact of higher quality on quality disclosure investments has been provided by Mathios (2000). There are, however, arguments that claim the opposite, particularly when pricing is endogenous and can be an alternative signaling mechanism. Chang and Wildt (1994) designed a 
laboratory experiment where they show that "price exerts a positive influence on perceived quality [...] moderated by the importance and amount of intrinsic information". The role of pricing as a signaling mechanism is well known (Wolinsky 1983; Milgrom and Roberts 1986a), but Chang \& Wildt show that it can substitute costly quality disclosure. The authors recommend that leading brands de-emphasize product information and focus more on using prices as a signaling mechanism.

There is also extensive literature on the impact of competition on quality disclosure. Jin (2005) observes that disclosure investments in the healthcare industry are lower in more competitive markets. However, Jin argues that because quality disclosure decisions are influenced by the underlying product quality, the manner in which competition impacts quality disclosure depends on the firms' quality choices; since the literature makes "ambiguous predictions" on the impact of competition to product quality (Tirole 1988), the relationship between competition and quality disclosure also depends on a complex combination of factors. Indeed, on the one hand, there is work that suggests that the presence of multiple firms sharpens the incentives for information revelation. This may be because under intense competition even small changes in quality perceptions become important (Stivers 2004), or because, when the market is unaware that the firms possess any new information, the announcement by one firm of news, signals to the market that other firms may also possess new information (Dye and Sridhar 1995). On the other hand, some researchers argue that as the number of firms increases, sellers avoid disclosing information that may actually sharpen the competition between them, especially if the information is related to production costs or demand functions that are privately known to oligopolists (Okuno-Fujiwara et al. 1990), or if the information revealed educates the consumers about the product category in general, in which case firms in more competitive markets will be less likely to disclose in order to prevent competitors from free riding on their efforts (Jin 2005). On the same theme of firms trying to alleviate price competition by withholding product information, Hotz and Xiao (2013) and Board (2009) present duopoly models where, under certain conditions, a firm may choose to withhold quality information, even if it is costless and can actually improve consumers' perceptions about the firm's quality.

Table 1 lists the relevant literature. In summary, most papers in the literature on quality uncertainty treat firms' quality choices as exogenous, effectively focusing on interaction A of Figure 1 - highlighted with darker color - at the expense of other interactions. Two notable exceptions are due to Economides (1993), with a perfect information model, and Albano and Lizzeri (2001), who present the first uncertainty model to include endogenous quality production in a monopoly setting. In the model of Albano and Lizzeri (2001) buyers cannot be informed by sellers but only by infomediaries, and the article's applicability is somewhat limited to markets with a certification authority, e.g., an auditor. In another model with similarities to ours, Chen and Xie (2005) investigate quality uncertainty and the role of infomediaries in a duopoly. In the model of Chen and Xie 


\begin{tabular}{|c|c|c|c|c|}
\hline Authors & Year & $\begin{array}{c}\text { Number } \\
\text { of Sellers }\end{array}$ & $\begin{array}{c}\text { Endogenous } \\
\text { Quality? }\end{array}$ & $\begin{array}{c}\text { Endogenous } \\
\text { Disclosure? }\end{array}$ \\
\hline Grossman and Hart & 1980 & $N, 1$ & No & Yes \\
\hline Grossman & 1981 & 1 & No & Yes \\
\hline Milgrom & 1981 & $N, 1$ & No & Yes \\
\hline Jovanovic & 1982 & $N$ Large & No & Yes \\
\hline Verrecchia & 1983 & 1 & No & Yes \\
\hline Matthews and Postlewaite & 1985 & 1 & No & Yes \\
\hline Dye & 1986 & 1 & No & Yes \\
\hline Milgrom and Roberts & $1986 \mathrm{~b}$ & $N, 1$ & No & Yes \\
\hline Okuno-Fujiwara et al. & 1990 & $N$ & No & Yes \\
\hline Economides & 1993 & $N$ & Yes & No \\
\hline Shavell & 1994 & $N$ & No & Yes \\
\hline Dye and Sridhar & 1995 & $N$ & No & Yes \\
\hline Albano and Lizzeri & 2001 & 1 & Yes & Yes \\
\hline Fishman and Hagerty & 2003 & 1 & $\mathrm{No}$ & Yes \\
\hline Stivers & 2004 & $N, 1$ & $\mathrm{No}$ & Yes \\
\hline Cheong and Kim & 2004 & $N$ Large & No & Yes \\
\hline Chen and Xie & 2005 & 2 & No & Yes \\
\hline Board & 2009 & 2 & No & Yes \\
\hline Levin et al. & 2009 & 1,2 & No & Yes \\
\hline Sun & 2011 & 1 & $\mathrm{No}$ & Yes \\
\hline Hotz and Xiao & 2013 & 2 & No & Yes \\
\hline Present Model & 2016 & $N$ & Yes & Yes \\
\hline
\end{tabular}

Table 1 A comparison of previous models with codified features

(2005) the authors focus solely on information disclosure and not on endogenous quality selection, or the impact of ambient information to product quality. Ours is the only model to include all the four key interactions identified in Figure 1. To the best of our knowledge it is the first model of a competitive market where both quality production and quality disclosure are endogenous decisions.

\section{Analytical Model and Solution 3.1. Model and Game Set-Up}

In a market of $N$ sellers, products are characterized by one taste and one quality characteristic. Following (Economides 1989), we represent this in the form of a cylindrical market (see Figure 2). The unit size circumference represents the taste (type) choices, while the cylinder's height is the 
quality attribute space. Thus our market is simply the Salop circular market (Salop 1979) extended vertically to include a quality dimension. Seller enumeration proceeds sequentially and sellers with sequential indexes are neighbors in the taste space. We further assume that sellers have positioned their products equidistantly in the taste-space ${ }^{2}$, at a distance of $1 / N$.

Each seller targets a specific quality level, denoted by $q_{r i}$ for Seller $\mathrm{S}_{\mathrm{i}}$, but random factors also influence the level of quality actually achieved. More specifically, a seller targets quality level $q_{r i}$ by incurring convex costs of quality of the form $C\left(q_{r i}\right)=k \cdot q_{r i}^{2} / 2$, but the actual level of quality achieved is $q_{i}=q_{r i}+\epsilon$, where $\epsilon$ is an error term, drawn from a uniform distribution in [ $\left.-r, r\right]$. The parameter $k$ controls the quality production cost for a given target quality $q_{r i}$. For example, Figure 2 depicts one instance of our model with four sellers $\mathrm{S}_{1}, \mathrm{~S}_{2}, \mathrm{~S}_{3}$ and $\mathrm{S}_{4}$ with $\left(d_{i}, q_{i}\right), i=1 \ldots 4$, as the type and quality of their products respectively. In the figure, Sellers $\mathrm{S}_{1}$ and $\mathrm{S}_{2}$ were not able to reach their targeted quality levels $q_{r 1}$ and $q_{r 2}$, while Sellers $\mathrm{S}_{3}$ and $\mathrm{S}_{4}$ were able to exceed them.

We assume that buyers can obtain perfect information about product types and prices, but not so for product quality, unless sellers invest to inform them. If the sellers do not invest in information disclosure, buyers can still obtain some quality information through other sources in the market (e.g. consumer reviews and third-party infomediaries). Specifically, buyers learn of an interval of size $\alpha$ that always includes the product's actual quality. A high value of $\alpha$ describes situations where there are few outside sources of product quality information and significant uncertainty. A lower value of $\alpha$ signifies that product quality information is readily available to buyers through infomediaries.

We call the interval of size $\alpha$ the seller's quality uncertainty interval, and we assume that a product may be located anywhere inside the uncertainty interval with equal probability: if a buyer observes this uncertainty interval, the buyer would form an expectation that $\mathrm{S}_{\mathrm{i}}$ 's quality is a random variable $\overline{q_{i}}$ with uniform $\operatorname{PDF} f_{q i}(\cdot)$ and support $\left[q_{i A}, q_{i B}\right]$, where $q_{i B}=q_{i A}+\alpha$. Thus, some products' true location would be at the lower end of the uncertainty interval (the product would appear to be better than it actually is), and others' would be at the higher end of the interval (the product's quality would appear lower than it actually is $)^{3}$.

\footnotetext{
${ }^{2}$ While horizontal differentiation is not a focus of our model, we retain a type dimension to ensure that sellers are sufficiently differentiated to have some captive market. In the absence of such a captive market, competition among sellers degenerates into a type of Bertrand competition in which a seller may want to advertise lower than actual quality (Gabszewicz and Thisse 1979). These cases are not typical in a study of quality disclosure, and we use the Salop circle to avoid them.

${ }^{3}$ As more information becomes available, the expected quality of the first product would appear to reduce, while the expected quality of the second product would appear to increase. Both cases, as well as the case of expected product quality remaining constant when more information emerges, are easily observable in real markets. For example, Li and Hitt (2008) document wide differences between how books sold on Amazon are initially perceived by buyers when buyer reviews about them are relatively sparse, and how the same books are perceived in the long run steady state, when enough reviews have accumulated.
} 


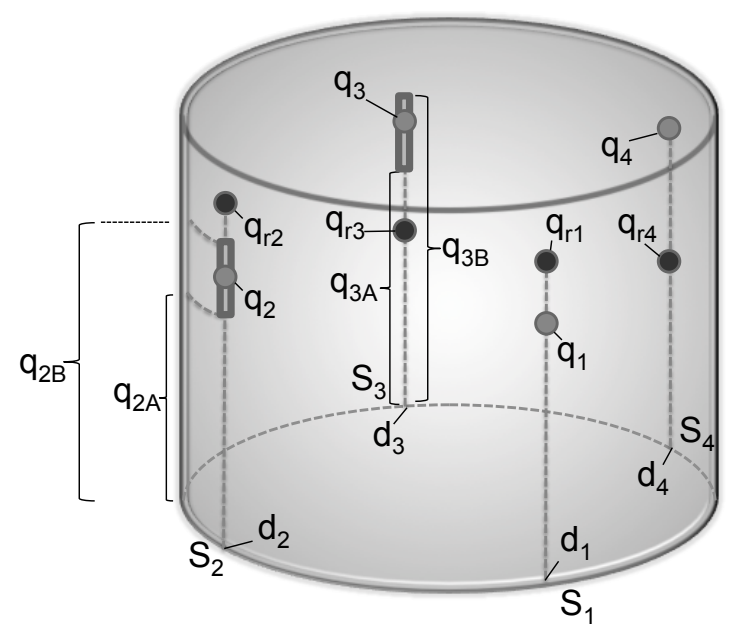

Figure 2 Our model of product differentiation and buyer uncertainty. In this particular model instance there are $N=4$ sellers. Sellers choose the level of quality investment, which specifies a target quality $q_{r i}$, but the actual final quality may differ, as it is also affected by random factors.

A way to interpret the operation of third party infomediaries is as follows: buyers who know or who can correctly anticipate the sellers' quality investments are uncertain about product quality within a range of $2 r$. Ambient market information, due to infomediaries, allows buyers to further reduce this uncertainty range from $2 r$ to $a$. The more information infomediaries provide ${ }^{4}$, the lower $a$ is assumed to be.

In our model, buyers take into account additional information (e.g., seller disclosure decisions) and will rationally update the prior $\left[q_{i A}, q_{i B}\right]$ before purchasing. Indeed, before purchasing, buyers will in general have formed uncertainty intervals of different sizes for different sellers, and will have perfect knowledge about the sellers that disclose their quality.

If sellers are dissatisfied by the level of information that buyers can get from infomediaries, they can invest in information disclosure, by incurring disclosure cost $c$. In Figure 2, Sellers $\mathrm{S}_{1}$ and $\mathrm{S}_{4}$ (depicted in the figure without an associated uncertainty interval) have chosen to disclose quality, while Sellers $\mathrm{S}_{2}$ and $\mathrm{S}_{3}$ have decided not to invest in quality disclosure ${ }^{5}$. In this particular model instance, buyers happen to somewhat underestimate the quality of Seller $\mathrm{S}_{3}$, as $q_{3}$ is located near the top of the quality uncertainty interval. At the same time, the buyers' average estimate for the quality of Seller $\mathrm{S}_{2}$ is approximately correct, as $q_{2}$ is located near the center of the quality uncertainty interval. ${ }^{6}$

${ }^{4}$ we require $a<<2 r$ for any substantial contribution of the infomediaries to buyer knowledge.

${ }^{5}$ We assume that sellers can only disclose truthfully. Previous authors have pointed out that "the prospect of litigation and of loss of future business is enough to stop the seller from making a false claim" (Jovanovic 1982).

${ }^{6}$ Throughout the paper we must assume that $q_{r i}-\alpha-r \geq 0$, that is $r$ and $\alpha$ cannot be so large that buyers would experience product uncertainty that would imply negative product quality. The exact restriction on the values of $r$ and $\alpha$ is easy to calculate given the equilibrium solution for target quality, that we derive below. 
Note that in our model the sellers are identical, except for their differentiation in the taste space. A treatment of the case where sellers are heterogeneous in their cost of quality production (parameter $k$ ) and cost of quality disclosure (parameter $c$ ) is provided in the Appendix. For all our main results, we discuss whether or not the result holds with heterogeneous sellers, and if not, we explain how to interpret the result in the presence of heterogeneous sellers.

All buyers demand one unit of the product. Each buyer is defined by his most preferred product location in the taste space $z$. Buyers are uniformly distributed around the cylinder's circumference in this respect. Because the circumference is unit size, the buyers' most preferred locations are distributed uniformly in $[0,1]$. The value to the buyer of purchasing a product with characteristics $\left(d_{i}, q_{i}\right)$ and price $p_{i}$ is $V\left(z, \sigma, d_{i}, q_{i}, p_{i}\right)=v+\sigma \cdot q_{i}-p_{i}-t \cdot\left|z-d_{i}\right|$, where $v$ is the buyer's utility from consuming a product at the minimum possible quality that is located at his most preferred type, $\sigma$ denotes the intensity of the buyer's preference for quality, and $t$ is the fit cost parameter, which denotes the disutility that the buyer experiences from consuming a product that is not his ideal. The parameter $t$ is common to all buyers. Following Economides (1993), we assume that consumers are heterogeneous in the preference for quality, and that $\sigma$ is drawn by some distribution $G$ with support $\left[0, \theta_{\max }\right]$, with expected value $E(\sigma)=\theta$. A usual additional assumption in spatial models is that $v$ is large enough so that all the market is served (Hotz and Xiao 2013; Soberman 2004). This is needed to avoid local monopolies which require substantially different analysis. The exact requirement for $v$ is shown along with the solution to the symmetric equilibrium, below.

A buyer with preferred product location $z$ and preference for quality $\sigma$, when purchasing from Seller $\mathrm{S}_{\mathrm{i}}$, expects utility $E(V)=v+\sigma \cdot E\left(\overline{q_{i}}\right)-p_{i}-t \cdot\left|z-d_{i}\right|$ where $E(\cdot)$ denotes expected value.

Let $s_{i} \in\{0, c\}$ denote the quality disclosure investment cost for Seller $\mathrm{S}_{\mathrm{i}}$, which is zero if the seller does not release quality information and $c>0$ otherwise. In addition, we assume that a seller's quality uncertainty is fully resolved upon investment by the firm. Revenue for firm $S_{i}$, in vector notation, is given by $R_{i}(\mathbf{p}, \mathbf{q})=p_{i} \cdot D_{i}(\mathbf{p}, \mathbf{q})$, and the profit is given by:

$$
\Pi_{i}(\mathbf{p}, \mathbf{q})=p_{i} \cdot D_{i}(\mathbf{p}, \mathbf{q})-C\left(q_{r i}\right)-s_{i}
$$

where $D_{i}$ denotes demand, $\mathbf{p}$ is the price vector $\mathbf{p}=\left(p_{1}, p_{2}, \ldots, p_{N}\right)$ and $\mathbf{q}$ is the vector of expected seller qualities $\mathbf{q}=\left(E\left(\overline{q_{i}}\right), E\left(\overline{q_{2}}\right), \ldots, E\left(\overline{q_{N}}\right)\right)$. Note that the quality production cost depends on the seller's target quality, but demand depends on the buyers' expectation about actual quality.

Assuming utility maximizing buyers and sellers, we define our game as follows:

Stage 1 Sellers choose their quality investment. 
... Sellers learn the quality level that they achieved, and they also learn how their products are perceived by early users in pre-market trials. They thus learn the uncertainty intervals that will be associated with their products if they do not invest in information disclosure ${ }^{7}$.

Stage 2 Sellers decide whether or not to invest in quality disclosure.

... Sellers and buyers learn the information of sellers who invested in disclosure, learn from infomediaries the uncertainty intervals of sellers who have not invested in disclosure, and update their expectations about product qualities.

Stage 3 Sellers choose their prices.

... Buyers enter the market and make their purchase decisions.

Note that we set up the game between sellers and buyers in the backdrop of information availability coming from Nature. When discussing the results, we attribute Nature's choices to infomediaries, so that our model better connects to real-world markets. However, infomediaries are not strategic players in our model, and any source of product information, other than the seller of the product, can assume the role that we assign to them.

\subsection{Analytical Solution}

We next present the equilibrium solution to the subgame comprised of Stages 3 and 2. The analysis of these stages is sufficient to intuitively understand our main results. We will then present the subgame perfect solution of the full game, leaving the analysis of Stage 1 for the Appendix.

\subsubsection{Pricing ${ }^{8}$}

At the start of Stage 3, qualities have been decided, and sellers have made their disclosure decisions. Buyers have taken into account sellers' disclosure decisions and have updated their expectations about sellers' qualities. Expected quality for Seller $\mathrm{S}_{\mathrm{i}}$ is denoted by $E\left(\overline{q_{i}}\right) .^{9}$

Let the marginal consumer who is indifferent between sellers $\mathrm{S}_{\mathrm{i}}$ and $\mathrm{S}_{\mathrm{i}+1}$ have type $z_{i}$. We can easily show that $z_{i}=\frac{1}{2 N}+\frac{p_{i+1}-p_{i}}{2 t}+\theta \frac{E\left(\overline{q_{i}}\right)-E\left(\overline{q_{i+1}}\right)}{2 t}$

Repeating the calculation for $z_{i-1}$, we derive the demand $z_{i}-z_{i-1}$ for Seller $\mathrm{S}_{\mathrm{i}+1}$ :

$$
D_{i}=\int_{0}^{\theta_{\max }} \int_{z_{i-1}}^{z_{i}} d z d G(\sigma)=\frac{1}{N}+\frac{p_{i+1}+p_{i-1}-2 p_{i}}{2 t}+\frac{\theta\left(2 E\left(\overline{q_{i}}\right)-E\left(\overline{q_{i+1}}\right)-E\left(\overline{q_{i-1}}\right)\right)}{2 t}
$$

${ }^{7}$ The mechanism is as follows: given that Seller $\mathrm{S}_{\mathrm{i}}$ has actual product quality $q_{i}$, Nature chooses a lower bound $q_{i A}$ for an uncertainty interval of size $\alpha<r$, by drawing $q_{i A}$ from the uniform distribution with bounds $\left[q_{i}-\alpha, q_{i}\right]$.

8 The analysis of this game stage closely follows Economides (1993).

${ }^{9}$ The information structure of the buyers at Stage 3 will be revealed when we analyze Stage 2 . In summary we will find that it is as follows. If the buyers observe that Seller $\mathrm{S}_{\mathrm{i}}$ disclosed at Stage 2, the buyers' expected quality $E\left(\overline{q_{i}}\right)$ for $\mathrm{S}_{\mathrm{i}}$ is $q_{i}$ (the buyers knows exactly what $\mathrm{S}_{\mathrm{i}}$ 's quality is). If the buyers observe that $\mathrm{S}_{\mathrm{i}}$ has not disclosed, the buyers exclude the upper part of the uncertainty interval and update their expectation for quality to be uniformly distributed in $\left[q_{i A}, \tilde{q}_{i}\right]$, where $\tilde{q}_{i}$ is given in Lemma 3. (buyers rationally reason that quality cannot fall in $\left[\tilde{q}_{i}, q_{i B}\right]$ because in that case the seller would have disclosed). Buyers' expected quality $E\left(\overline{q_{i}}\right)$ for $\mathrm{S}_{\mathrm{i}}$ at the start of Stage 3 is the mid point of the interval $\left[q_{i A}, \tilde{q}_{i}\right]$. At the start of Stage 3, Seller $S_{i}$ takes buyers expectation of $E\left(\overline{q_{i}}\right)$ as given, because he cannot influence this expectation by signaling through his price: if such a signal existed, it would be costlessly exploited by all sellers to signal the maximum possible quality and would carry no information to a rational buyer. 
Thus, a firm captures half the buyers that are in between its closest two competitors in the taste space (first term) adjusted for price differences (second term) and quality differences (third term).

Differentiating Equation 1 with respect to price yields: $p_{i}-\frac{\left(p_{i-1}+p_{i+1}\right)}{4}=\frac{t}{2 N}+$ $\frac{\theta\left(2 E\left(\overline{q_{i}}\right)-E\left(\overline{q_{i+1}}\right)-E\left(\overline{q_{i-1}}\right)\right)}{4}$. Substituting into Equation 2 we get $D_{i}^{*}=p_{i}^{*} / t$ and thus:

$$
\Pi_{i}^{*}\left(p_{i}^{*}, \mathbf{q}, \mathbf{d}\right)=p_{i}^{* 2} / t-C\left(q_{i}\right)-s_{i}
$$

In the pricing subgame, sellers have already chosen their product details and have made their disclosure decisions. Seller $\mathrm{S}_{\mathrm{i}}$ maximizes profits with respect to price $p_{i}$ (Equation 1) when: $p_{i}-$ $\frac{p_{i-1}}{4}-\frac{p_{i+1}}{4}=\frac{t}{2 N}+\frac{\theta}{4}\left(2 E\left(\overline{q_{i}}\right)-E\left(\overline{q_{i+1}}\right)-E\left(\overline{q_{i-1}}\right)\right)$. In matrix form:

$$
\mathbf{A} \cdot \mathbf{p}=\frac{t}{2 N}+\theta \cdot \mathbf{H} \cdot \mathbf{q}
$$

where matrix $\mathbf{A}$ has $A_{i}=\left[A_{i, 1}=0, A_{i, 2}=0, \ldots, A_{i, i-1}=\frac{-1}{4}, A_{i, i}=1, A_{i, i+1}=\frac{-1}{4}, \ldots, A_{i, N}=0\right]$, $\mathbf{q}$ is the vector with $q_{i}=E\left(\overline{q_{i}}\right)$, and $H=A-I / 2$, with $\mathbf{A}, \mathbf{H}$ circulant symmetric matrices of constants, so that the inverse of $\mathbf{A}$ exist, because the sum of the first row elements is non-zero.

Since $\mathbf{A}, \mathbf{H}$ are invertible, Equation 4 has a unique solution with

$$
p^{*}(\mathbf{q})=\mathbf{A}^{-1}\left(\frac{t}{2 N} \cdot \mathbf{1}+\theta \cdot \mathbf{H} \cdot \mathbf{q}\right) \equiv \mathbf{A}^{-1} \cdot \mathbf{e}(\mathbf{q})
$$

Let $b_{k}$ denote the element of the diagonal at distance $|k|$ from the main diagonal of $\mathbf{A}^{-1}$. Then:

$$
p_{i}^{*}=\sum_{j=-N / 2}^{N / 2} b_{j} e_{j+i}(\mathbf{q})
$$

Figure 3 depicts the pricing equilibrium for $N=5$ sellers, and helps us visualize $p_{i}^{*}$. The next two lemmas explain how equilibrium price responds to changes in expected quality. Intuitively, the lemmas show that an increase in expected quality allows a seller to increase his equilibrium price, but an increase in the expected quality of a competitor, forces a seller to reduce his equilibrium price by an amount that depends on how close a neighbor (in the taste space) that competitor is. Closer taste-space neighbors have greater impact on each other's prices.

Lemma $1 . d p_{i}^{*} / d E\left(\overline{q_{i}}\right)=\theta \cdot b / 2$, where $b=b_{0}-b_{1}$

Proof: $\quad d p_{i}^{*} / d E\left(\overline{q_{i}}\right)=\sum_{j=N / 2}^{N / 2} b_{j}\left(d e_{i+j}(\mathbf{q}) / d E\left(\overline{q_{i}}\right)\right)=b_{0} \theta / 2-b_{1} \theta / 4-b_{-1} \theta / 4=\theta \cdot b / 2>0$, since $b_{i}=b_{-i}$ and $b=b_{0}-b_{1}$ is always positive (Economides 1993).

Lemma 2. $d p_{i}^{*} / d E\left(\overline{q_{j}}\right)=-\theta \cdot b_{m} / 2$, for $i \neq j$, where $m=j-i$

Proof: From Equation 6 (see also Figure 3), $d p_{i}^{*} / d E\left(\overline{q_{j}}\right)=\theta\left(b_{m} / 2-b_{m-1} / 4-b_{m+1} / 4\right)=$ $-\theta \cdot b_{m} / 2$, because $4 b_{m}=b_{m+1}+b_{m-1}, \forall m \neq 0$, by the properties of $\mathbf{A}^{-1}$. 


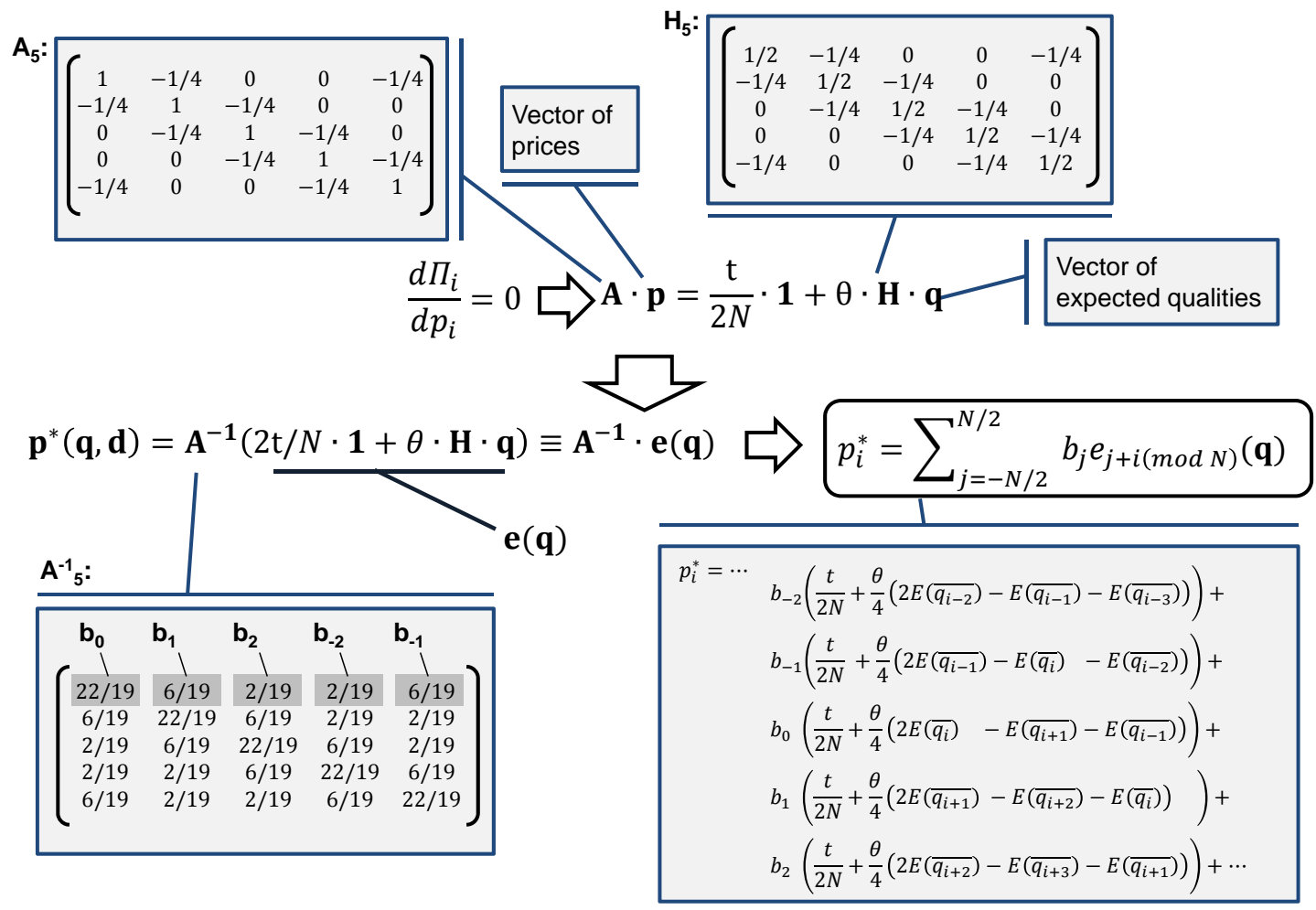

Figure 3 Equilibrium solution of the pricing stage for $N=5$.

Lemma 2 says that if the expected quality of seller $S_{j}$ increases by $\chi$, Seller $S_{\mathrm{i}}$ 's equilibrium price would decrease by $\theta \cdot b_{m} \cdot \chi / 2$, where $m=j-i$. This can be seen in Figure 3: if $\mathrm{S}_{2}$ increased his quality by $\chi, \mathrm{S}_{0}$ would have to respond to the price decreases of $\mathrm{S}_{1}$ and $\mathrm{S}_{3}$ that push $\mathrm{S}_{0}$ price downwards by $-\theta \cdot \chi \cdot\left(b_{1} / 4+b_{-2} / 4\right)$. To see this in Figure 3, note that from the point of view of $\mathrm{S}_{0}$, only $E\left(\overline{q_{i+2}}\right)$ and $E\left(\overline{q_{i-3}}\right)$ contribute with minus signs, as they both refer to $\mathrm{S}_{2}$. But $\mathrm{S}_{2}$ would actually increase his price, as per Lemma 1 , so that $\mathrm{S}_{0}$ 's price would be somewhat pushed up by $\theta \cdot \chi \cdot b_{2} / 2$. This comes from the term $E\left(\overline{q_{i+2}}\right)$ that appears in the coefficient of $b_{2}$. Summing up these price adjustments $S_{0}$ would end up decreasing his price by $\theta \cdot \chi \cdot\left(b_{2} / 2-b_{1} / 4-b_{-2} / 4\right)=-\theta \cdot \chi \cdot b_{2} / 2$.

Figure 3 reveals that all sellers influence each other's choices, but closer neighbors influence each other much more so than sellers that are further away. In the case of $N=5$ products, the influence on a seller's price of his two immediate neighbors is 3 times greater than the influence of the sellers that are two products apart (in $\mathbf{A}_{5}^{-1}$ we observe that $b_{1} / b_{2}=3$ ). This means that a neighbor's change in quality causes 3 times greater response in the seller's price than the same change in quality of a seller that is two products apart. The influence of products that are further and further away diminishes quickly. For example for $N=11$ a seller responds to a neighbor's quality change with a price adjustment that is 153 times greater than the adjustment by which he responds to the same quality change of a seller that is 4 products apart $\left(b_{1} / b_{5}=153\right.$ in the $\mathbf{A}_{11}^{-1}$ matrix). 
3.2.2. The Information Disclosure Investment Stage The information structure at this Stage is as follows. Each Seller $S_{i}$ knows its own quality and has received information about how Nature realized its quality uncertainty interval. Buyers have not yet made any observations, they will learn of quality uncertainty intervals and sellers' disclosure decisions at the end of Stage $2 .^{10}$ Finally, sellers anticipate that in the pricing stage they will price according to Equation 6 .

Lemma 3. Given Seller $\mathrm{S}_{\mathrm{i}}$ 's quality uncertainty interval $\left[q_{i A}, q_{i B}\right]$, there exists a quality level $\tilde{q}_{i} \in\left[q_{i A}, q_{i B}\right]$, so that $\mathrm{S}_{\mathrm{i}}$ discloses if, and only if, $q_{i}>\tilde{q}_{i} \Leftrightarrow q_{i} \in\left[\tilde{q}_{i}, q_{i B}\right]$,

Proof: Using Equation 3 and Lemma 1, a seller's profit (minus the required disclosure cost) is increasing in perceived quality: $\frac{d\left(\Pi_{i}^{*}-s_{i}\right)}{d E\left(\overline{q_{i}}\right)}=\frac{d R_{i}^{*}}{d E\left(\overline{q_{i}}\right)}-\frac{d C\left(q_{i}\right)}{d E\left(\overline{q_{i}}\right)}=\frac{2 p_{i}^{*}}{t} \cdot \frac{d p_{i}^{*}}{d E\left(\overline{q_{i}}\right)}$ (the quality production cost has already been incurred in Stage 2, so that now $\left.\frac{d C\left(q_{i}\right)}{d E\left(\overline{q_{i}}\right)}=0\right)$. Further, buyers know that sellers know their actual quality and their uncertainty intervals, and disclosure of quality information entails a cost $c$. Thus, our model satisfies the assumptions of the classic analysis of costly quality disclosure (Verrecchia 1983; Fishman and Hagerty 2003) so that quality information unravels above a threshold, which we denote as $\tilde{q}_{i}$.

If Seller $\mathrm{S}_{\mathrm{i}}$ does not disclose, buyers conclude that his quality cannot be uniformly distributed in $\left[q_{i A}, q_{i B}\right]$. Instead, they trim the upper part of the quality uncertainty interval and expect quality to be uniformly distributed in $\left[q_{i A}, \tilde{q}_{i}\right]$ by arguing that if quality exceeded $\tilde{q}_{i}$ the seller would have disclosed. Thus rational buyers would reduce their expectation of the Seller $\mathrm{S}_{\mathrm{i}}$ quality to:

$$
\underline{q_{i}}=\frac{q_{i A}+\tilde{q}_{i}}{2}
$$

$\tilde{q}_{i}$ is such that if $\delta_{i} \equiv \tilde{q}_{i}-\underline{q_{i}}$ then $R_{i}^{*}\left(\tilde{q}_{i}\right)-c=R_{i}^{*}\left(\tilde{q}_{i}-\delta_{i}\right)$, so that the revenue that a seller with quality $\tilde{q}_{i}$ gives up by withholding quality information, is offset by disclosure cost savings. It is easy to verify that $\tilde{q}_{i}=q_{i A}+2 \delta_{i}$, so that we can calculate $\tilde{q}_{i}$ using Equation 9 in the Appendix for the value of $\delta_{i} \cdot{ }^{11}$

To summarize, sellers disclose quality information if and only if their quality exceeds the threshold $\tilde{q}_{i}$ within their quality uncertainty interval (exceeds the lower end of their uncertainty interval by $\left.2 \delta_{i}\right)$. In general, it may happen that a lower quality seller exceeds this quality threshold inside her own uncertainty interval, but that a higher quality seller does not (see Figure 5 in Section 4.1).

\footnotetext{
${ }^{10}$ If the buyers were to observe the realization of the uncertainty intervals at this point, they would rationally believe quality to be uniformly distributed in $\left[q_{i A}, q_{i B}\right]$.

${ }^{11}$ In general $\tilde{q}_{i}$ may not be unique. However in our case it is. The more complex equation for $\underline{q_{i}}$ is $\underline{q_{i}}=$ $\int_{q_{i A}}^{\tilde{q_{i}}} \frac{x f_{q i}(x)}{F_{q i}\left(\tilde{q_{i}}\right)-F_{q i}\left(q_{i A}\right)} d x=\int_{q_{i A}}^{\tilde{q_{i}}} \frac{x f_{q i}(x)}{F_{q i}\left(\tilde{q_{i}}\right)} d x=\frac{q_{i A}+\tilde{q_{i}}}{2}$, where $f_{q i}(\cdot)$ and $F_{q i}(\cdot)$ are the PDF and CDF of $\overline{q_{i}}$ (the random variable that corresponds to the actual location of $q_{i}$ inside the uncertainty interval). Because the uniform $f_{q i}(\cdot)$ is a $\log$-concave function, we can show that given $q_{i A}, \delta_{i}$ is increasing in $\tilde{q}_{i}$ (Bagnoli and Bergstrom 2005), and thus $\tilde{q}_{i}$ is unique, given $f_{q i}(\cdot)$. See (Cheong and Kim 2004). $f$ is log-concave if $\ln (f)$ is concave in its support (e.g., uniform, normal, etc.).
} 
3.2.3. The Quality Investment Choice Stage The analysis of Stages 3 and 2 suffices for the intuitive understanding of the paper's main results. The analysis of Stage 1 (quality investment choice) is instead presented in the Appendix.

3.2.4. Equilibrium Description Before discussing our results in Section 4, we describe the sub-game perfect equilibrium. In the Appendix, we show that:

THEOREM 1. For $\theta<\frac{2 t / N-2 \sqrt{c \cdot t}}{b \cdot r}$ and $v>\max _{\mathbf{q}, i}\left(p_{i}+\frac{t}{2 N}\right)$, the subgame-perfect equilibrium to the multi-stage game is as follows ${ }^{12}$ :

Stage 1 Sellers set quality targets given by:

$$
q_{r i}^{*}= \begin{cases}\frac{b \cdot \theta}{k \cdot N} & \text { if } c>c^{\prime} \\ \frac{b \cdot \theta}{k \cdot N}-A & \text { if } c^{\prime \prime}<c<c^{\prime} \\ \frac{b \cdot \theta}{k \cdot N}-B & \text { if } c<c^{\prime \prime}\end{cases}
$$

where $A, B$ are given in the Appendix (Lemma 8), $c^{\prime}$ is the information disclosure cost beyond which sellers always withhold information regardless of their quality realization, and $c^{\prime \prime}$ is the information disclosure cost below which sellers have non-zero disclosure probability regardless of their quality realization. Both $c^{\prime}$ and $c^{\prime \prime}$ are given in Lemma 6.

Stage 2 Seller $\mathrm{S}_{\mathrm{i}}$ will disclose quality if and only if his quality exceeds the lower limit of his quality uncertainty interval by

$$
\varphi=\frac{4}{\theta \cdot b}\left(\frac{t}{N}+\frac{\epsilon \cdot \theta \cdot b}{2}-\sqrt{\left(\frac{t}{N}+\frac{\epsilon \cdot \theta \cdot b}{2}\right)^{2}-t \cdot c}\right) .
$$

where $\epsilon$ is the realization of the error term which measures the Seller's deviation from his quality target, with $\epsilon \in[-r, r]$,

Stage 3 Firms' ex-ante expected price is $p^{*}=t / N$. Actual prices depend on the realization of qualities and quality uncertainty intervals, and are given by Equation 6:

$$
p_{i}^{*}=\sum_{j=-N / 2}^{N / 2} b_{j} e_{j+i}(\mathbf{q})
$$

In Figure 4 we show an example outcome of the game in a market of $N=3$ sellers. Given the parameter values shown in the figure legend, all sellers invest $\$ 0.88$, targeting quality level 1.4, denoted with a line around the cylinder's circumference. The sellers' expected profit across all

\footnotetext{
${ }^{12}$ For equilibrium to exist, $\theta$ is restricted not to be too large. Above the threshold specified, intense quality competition leads to high quality production costs that prevent firms from obtaining a positive profit. It is also easy to show that this restriction on $\theta$ suffices for the roots that appear in $L 1$ and $L 2$ to be positive. In the expression for $v$ we account for the need to have a fully served market, even for buyers with zero sensitivity on quality $(\sigma=0)$
} 


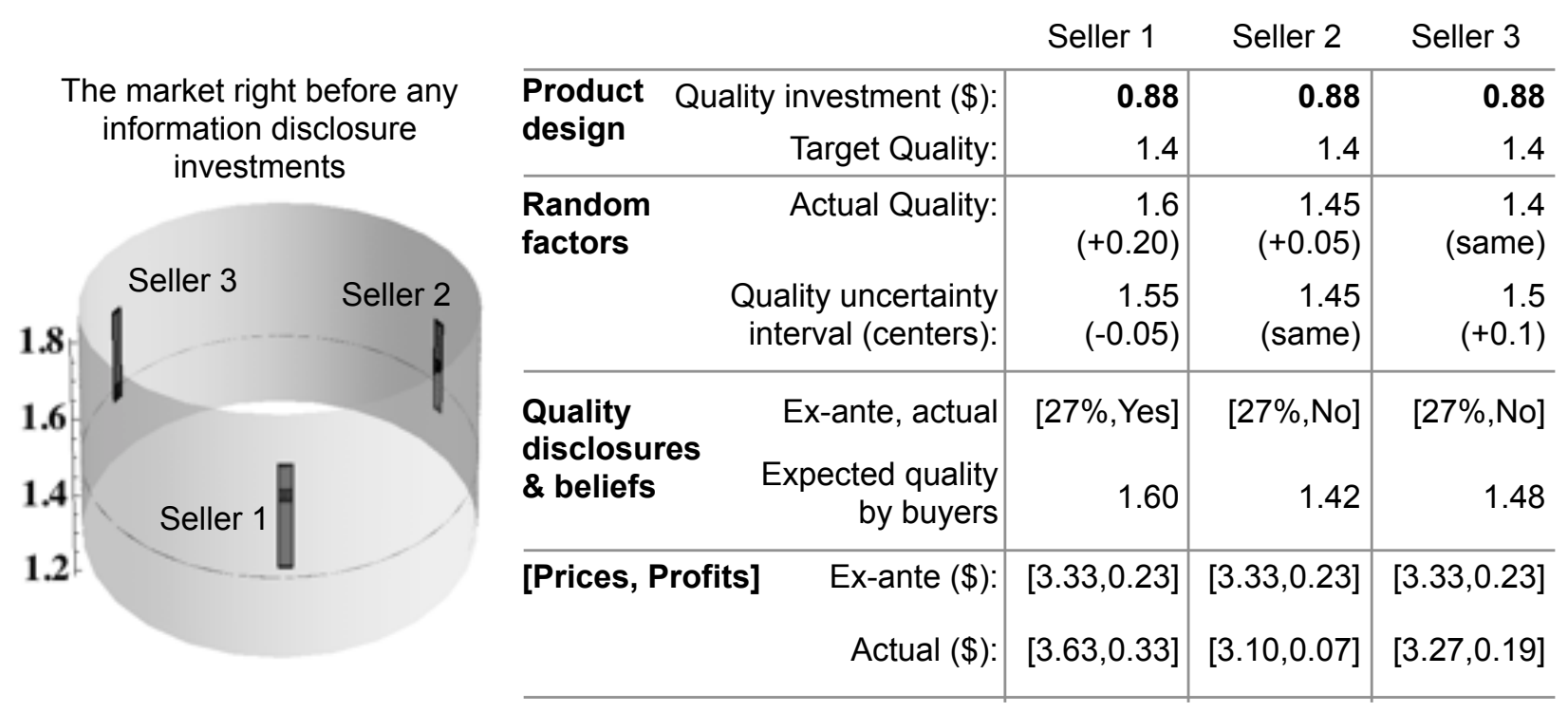

Figure 4 An example game outcome with three sellers. The values of the parameters used are $N=3, \alpha=0.25, c=0.1, k=0.9, \theta=5, t=10, r=1$

possible realizations for actual product qualities and quality uncertainty intervals is 0.23 , and their expected product price is 3.33 (which is simply $t / N$ ). At this quality investment level, the prior probability that any given seller will end up investing in quality disclosure is $27 \%$.

Random factors are assumed to be as follows. Both Seller $S_{1}$ and $S_{2}$ receive a favorable draw of $\epsilon$ and therefore surpass the expected quality level of 1.4 with their $\$ 0.88$ investment: $\mathrm{S}_{1}$ by 0.2 , and $\mathrm{S}_{2}$ by 0.05 . Actual product qualities are denoted with the small dark squares within the sellers' quality uncertainty intervals, depicted by the lighter-shaded rectangles. These intervals of length $\alpha=0.25$, which are randomly drawn conditionally on each seller's actual quality level, represent buyers' uncertainty about the true quality of each seller. Note that the center of each uncertainty interval represents buyer's expectation of each seller's quality, $E\left(\overline{q_{i}}\right)$. As we can see, the actual qualities of $\mathrm{S}_{1}$ and $\mathrm{S}_{2}$ are above the 1.4 quality line, while $\mathrm{S}_{3}$ 's quality is exactly on the line. $\mathrm{S}_{1}$ is not favored by Nature's draw of uncertainty intervals: the center of $\mathrm{S}_{1}$ 's uncertainty interval, as can be seen in the figure, is 0.05 units below his actual quality. $\mathrm{S}_{2}$ 's uncertainty interval happens to be centered exactly on his actual quality, while $S_{3}$ is heavily favored by Nature with an uncertainty interval whose center is 0.1 units above his actual quality.

The impact of these random factors is as follows. $\mathrm{S}_{1}$ is favored by Nature, and ends up with the highest actual product quality. However, buyers somewhat underestimate his true quality, so that $\mathrm{S}_{1}$ responds by investing in quality disclosure, despite the relatively low $27 \%$ prior on disclosure probability. This happens because, as per Theorem 1, the threshold for disclosure for Seller $\mathrm{S}_{1}$ is 0.013 quality units above the center of the uncertainty interval. Seller $\mathrm{S}_{1}$ 's quality is 0.05 units 
above the center of the uncertainty interval, so it is above the threshold. Consequently, buyers end-up learning $S_{1}$ 's quality and the seller is able to charge $\$ 3.63$ for his product, versus the $\$ 3.33$ ex-ante expected price. Despite incurring the $\$ 0.1$ quality investment cost, his $\$ 0.33$ profit exceeds the ex-ante expected profit of $\$ 0.23 . \mathrm{S}_{2}$ is, on the contrary, not favored by Nature's draws. Despite his somewhat better than expected actual quality of 1.45 , neighboring with the high quality $\mathrm{S}_{1}$ forces $\mathrm{S}_{2}$ to lower his price to $\$ 3.1$ and accept a lower than expected profit of $\$ 0.07$. Using Theorem 1 we can again verify that the quality disclosure threshold for Seller $S_{2}$ is 0.034 units above the center of the uncertainty interval, which is above $\mathrm{S}_{2}$ 's quality so that $\mathrm{S}_{2}$ does not disclose. This causes buyers to somewhat underestimate his quality (1.42 versus 1.45), but $\mathrm{S}_{2}$ is content to operate this way: saving on the quality investment cost more than justifies the additional price decrease (on top of the decrease caused by $S_{1}$ unexpectedly high quality) that $S_{2}$ is forced to concede. Finally, things are relatively better for $\mathrm{S}_{3}$ who is heavily favored by Nature's draws of uncertainty intervals, with the center of his uncertainty interval 0.1 units above his actual quality (1.5 versus 1.4). As expected, $\mathrm{S}_{3}$ is happy to forgo quality disclosure, causing buyers to scale-back their expected quality for the seller to 1.48 (versus uncertainty interval center of 1.5), which is still comfortably higher than his actual 1.4 quality. Buyers' relatively high expectations for $\mathrm{S}_{3}$ 's quality, combined with the savings from the forgone quality disclosure investment, allow $S_{3}$ to largely recover from having an unexpectedly high quality neighbor attack his market share, and $\mathrm{S}_{3}$ ends up with a price and final profit that are only somewhat lower than their ex-ante expected values.

\section{Results and Managerial Implications}

A roadmap of the main results that are explored next is given in Table 2

\subsection{Information Disclosure Investments}

At the end of the game, each Seller $\mathrm{S}_{\mathrm{i}}$ would either have disclosed, or not, depending on whether or not actual quality exceeds the lower end of his uncertainty interval by $2 \delta_{i}$, where $\delta_{i}$ was defined in Section 3.2.2. However, at the end of the quality selection stage (Stage 1), after sellers learn their achieved quality, but before they learn how Nature has chosen their quality uncertainty intervals, they know that the probability of disclosure $\operatorname{Pr}_{i}\left(q_{i}\right)$, given quality $q_{i}$ is:

$$
\operatorname{Pr}_{i}\left(q_{i}\right)=\operatorname{Prob}\left(q_{i}>\tilde{q}_{i}\right)=1-2 \delta_{i} / \alpha
$$

In the Appendix, we prove the following Proposition (the intuition is discussed below).

Proposition 1. Let $\operatorname{Pr}_{i}\left(q_{i}\right)$ be the probability that Seller $\mathrm{S}_{\mathrm{i}}$ will disclose, given quality $q_{i}$. Then $\operatorname{Pr}_{i}\left(q_{i}\right)$ can only increase in $q_{i}$. Moreover, the relationship is continuous. 


\begin{tabular}{|c|c|c|c|c|}
\hline Key Question & Result & Intuition & Analysis & $\begin{array}{c}\text { Inter- } \\
\text { actions }\end{array}$ \\
\hline $\begin{array}{l}\text { How sellers } \\
\text { account for } \\
\text { quality when they } \\
\text { invest to reduce } \\
\text { buyer uncertainty }\end{array}$ & $\begin{array}{l}\text { Higher quality sellers } \\
\text { invest more in } \\
\text { reducing quality } \\
\text { uncertainty }\end{array}$ & $\begin{array}{l}\text { Buyers rationally } \\
\text { apply larger discount } \\
\text { to higher quality } \\
\text { products that do not } \\
\text { disclose }\end{array}$ & $\begin{array}{l}\S 4.1, \\
\text { Proposition } 1, \\
\text { Figures } 5,6\end{array}$ & $\mathrm{~A}$ \\
\hline $\begin{array}{l}\text { How sellers } \\
\text { account for future } \\
\text { information } \\
\text { investments when } \\
\text { investing in } \\
\text { quality }\end{array}$ & $\begin{array}{l}\text { Sellers moderate } \\
\text { quality investment, } \\
\text { compared to the } \\
\text { perfect information } \\
\text { case }\end{array}$ & $\begin{array}{l}\text { Increasing quality also } \\
\text { increases probability } \\
\text { that a disclosure } \\
\text { investment may be } \\
\text { needed (reducing } \\
\text { quality ROI) }\end{array}$ & $\begin{array}{l}\S 4.2, \\
\text { Proposition } 2, \\
\text { Figure } 7\end{array}$ & $\mathrm{~A}, \mathrm{~B}$ \\
\hline $\begin{array}{l}\text { How sellers } \\
\text { account for } \\
\text { ambient } \\
\text { information } \\
\text { availability when } \\
\text { investing to } \\
\text { inform consumers }\end{array}$ & $\begin{array}{l}\text { External information } \\
\text { availability enables } \\
\text { sellers, and especially } \\
\text { lower quality ones, } \\
\text { to free ride }\end{array}$ & $\begin{array}{l}\text { Third party } \\
\text { information reduces } \\
\text { the maximum amount } \\
\text { by which buyers } \\
\text { discount non-disclosing } \\
\text { products }\end{array}$ & $\begin{array}{l}\S 4.3, \\
\text { Propositions } 3,4 \\
\text { Figures } 8,9\end{array}$ & $\mathrm{~A}, \mathrm{C}$ \\
\hline $\begin{array}{l}\text { How sellers } \\
\text { account for } \\
\text { ambient } \\
\text { information } \\
\text { availability when } \\
\text { investing in } \\
\text { quality }\end{array}$ & $\begin{array}{l}\text { Improvements in } \\
\text { external information } \\
\text { availability, may } \\
\text { enable sellers to } \\
\text { reduce quality } \\
\text { investments }\end{array}$ & $\begin{array}{l}\text { Quality becomes a less } \\
\text { important determinant } \\
\text { of profit as a quality } \\
\text { increase is more likely } \\
\text { to lead to future } \\
\text { disclosure costs }\end{array}$ & $\begin{array}{l}\S 4.4, \\
\text { Proposition } 5, \\
\text { Figure } 10\end{array}$ & $\mathrm{~A}, \mathrm{~B}, \mathrm{C}, \mathrm{D}$ \\
\hline
\end{tabular}

Table 2 Roadmap for the discussion of our main results

Proposition 1 is also true for target product quality $q_{r i}$ : the probability of disclosure can only increase with $q_{r i}$ since it is trivial to show that expected actual product quality cannot decrease as target product quality increases. Further, Proposition 1 takes quality $q_{i}$ as given, without making any assumptions about how the quality level came to be. Thus, the Proposition would still be valid even in a model with heterogeneous sellers. For instance, sellers that differ in their cost of quality production $k$ or quality disclosure $c$ (see Appendix B and the Online Appendix).

It is perhaps intuitively expected that the higher the quality of a product, the higher the seller's profit, in case of disclosure. This is in general agreement with most literature on the topic (Jovanovic 1982; Farrell 1986; Verrecchia 1983; Dye 1986; Shavell 1994). However, the model shows something more subtle: the higher the expected quality of a product, the more the buyers will discount its quality, should the seller fail to invest in information disclosure. For example: assume that buyers expect ex-ante that a seller's quality is uniformly distributed between 4 and 5 units (expected quality is 4.5). Upon observing that the seller has not disclosed, buyers discount his quality and 

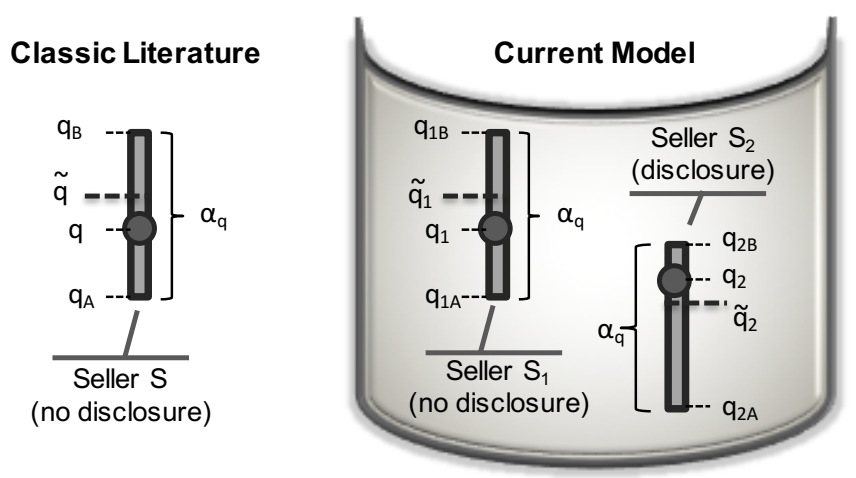

Figure 5 The quality disclosure mechanism in our model, as a refinement of the classic literature.

form new expectations in a range between 4 and $5-x$ units. Assume now that the buyers expect exante that another seller's quality is uniformly distributed between 2 and 3 units (expected quality is 2.5). Upon observing that the seller failed to invest in quality disclosure, buyers discount the seller's quality and form new expectations in a range between 2 and $3-y$, where $y<x$.

The intuition is as follows: Profits are convex in expected product quality because an increase in quality allows a seller to increase his price (Equation 6) while simultaneously gaining market share in the taste space (Equation 2). With convexity, for a given quality improvement, a higher quality seller increases profit more than a lower quality seller does. Thus, a higher quality seller would invest to improve buyers' perception even by a small amount, or equivalently, would invest to prevent even a small decrease of buyers' expectations about its quality. In other words, buyers argue that a higher quality seller would surely, if he could, disclose to prevent them from forming an expectation for quality close to the lower limit of the uncertainty interval, while a lower quality seller would not necessarily do so. Thus, a non-disclosing higher quality seller signals that he cannot prevent buyers from expecting quality to be at the lower end of the uncertainty interval, because this is actually where his true quality lies, and a disclosure would not help in his case.

The mechanism of quality disclosure of our model extends the classic literature that describes how quality information unravels when disclosure is costly. For example in (Jovanovic 1982) only sellers beyond a quality threshold (denoted by $\tilde{q}$ in Figure 5) disclose. Consequently, classic literature favors a quality cut-off approach. A quality improvement does not cause the firm to incur increased disclosure costs in the future, unless the quality improvement happens to span the disclosure threshold. In the current model, while quality unraveling still occurs inside the uncertainty intervals and while sellers disclose if their quality exceeds a threshold inside the uncertainty interval, disclosure is probabilistic, since the process that determines the exact position of the uncertainty interval is probabilistic. Thus, it could happen that a lower quality seller, such as $\mathrm{S}_{2}$ in Figure 5 , exceeds its threshold and discloses, while a higher quality seller, such as $\mathrm{S}_{1}$ does not exceed its 


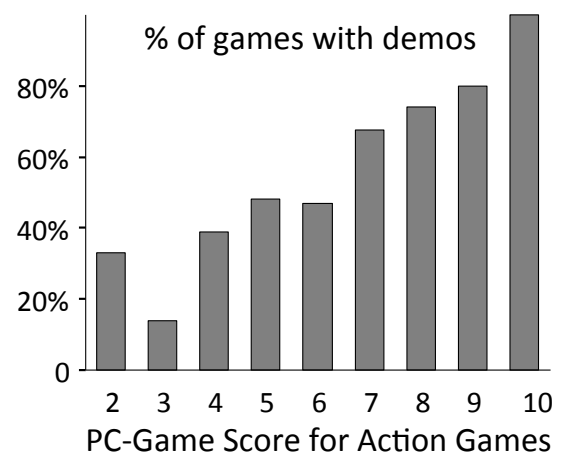

Figure 6 Disclosure probability as a function of product quality in the PC-Game market

threshold and fails to invest to reduce consumer uncertainty. However, this is not the most likely outcome. As per our previous discussion, the higher a seller's quality, the more willing it would be to disclose and thus the lower the disclosure threshold of the firm inside its uncertainty interval. This means that as quality increases, the disclosure threshold decreases, and higher quality sellers are more likely to disclose than lower quality sellers. The probability of disclosure as a function of quality is given by Lemma 5 in the Appendix, where it can be seen that it also depends on the strength of consumers' preferences for quality (firms are more likely to disclose if buyers value quality more), as well as on the size of the uncertainty interval, as we will discuss in Section 4.3.

To test if disclosure patterns in the real-world are consistent with Proposition 1, we gathered data on 2,196 PC-games released between 1996 and 2005, from the gaming website GameSpot. Game developers had a choice to invest in developing playable demo versions of their games, which could reduce buyer uncertainty about the quality of the game but were also expensive to develop. In Figure 6, we show the percent of PC-games of the Action genre $(N=418)$ that have invested in producing a playable demo version. The graph clearly shows that the higher the game quality, the greater the probability of the game developer having invested in the development of a playable demo version. We obtain similar results across game genres, and across release dates.

\subsection{Quality Production Decisions}

Proposition 2. Quality investment under uncertainty is at most equal to equilibrium quality under perfect information ${ }^{13}$.

Proof: $\quad$ Follows from Lemma 8, by showing that $A$ and $B$ are positive. This is true as long as $\theta<\frac{2 t / N-2 \sqrt{c \cdot t}}{b \cdot r}$, as we assumed for Theorem 1 . Note that quality investment does not monotonically decrease as $\alpha$ increases. Their more complex relationship is the subject of Proposition 5.

\footnotetext{
13 The idea of quality underinvestment under uncertainty was first discussed in (Jovanovic 1982), but was first shown explicitly by Albano and Lizzeri (2001).
} 

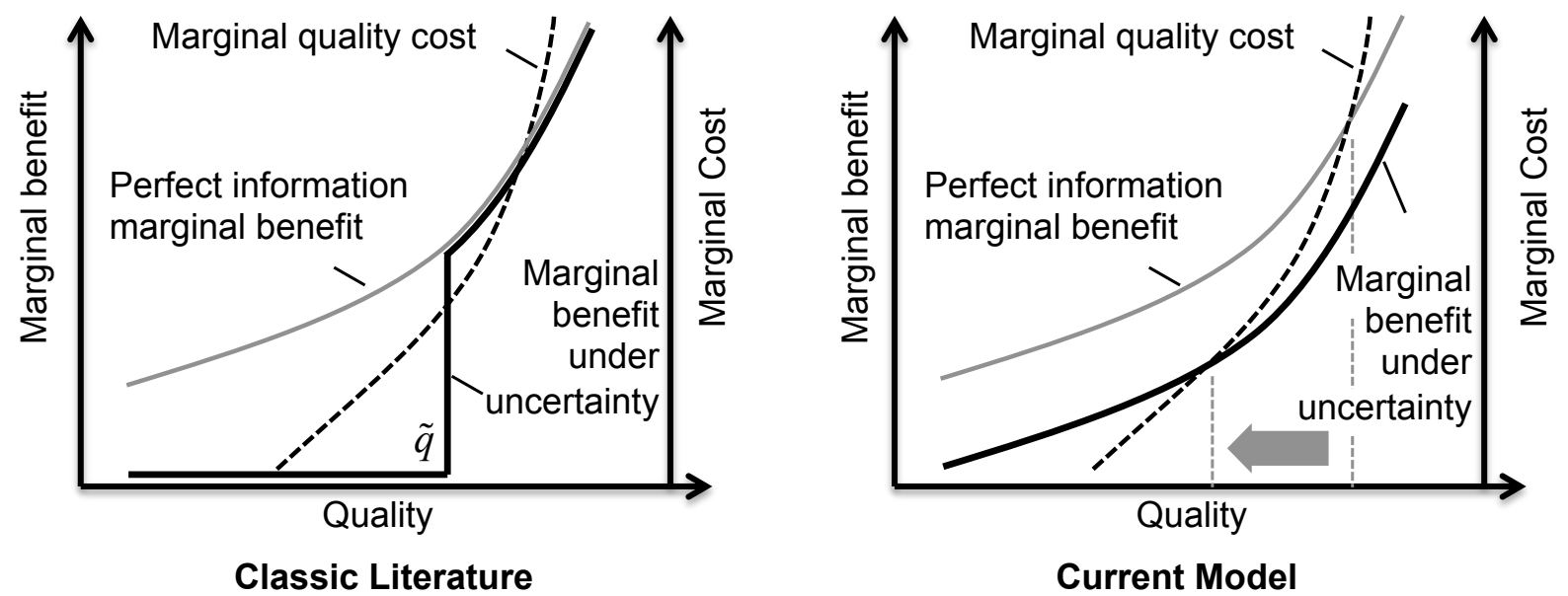

Figure 7 The mechanism of quality production in our model, as a refinement of the classic literature

In the case of heterogeneous sellers, Proposition 2 should be viewed as referring to the average prevailing quality in the market, and may not hold for each seller individually (see Appendix B and the Online Appendix).

The cost of disclosure, $c$, is the same in our model independent of the seller's quality. It is then surprising that this cost causes the seller to moderate the quality investment. The intuition is as follows. In the previous section we saw that the probability of quality disclosure increases with product quality, because buyers discount the quality of a non-disclosing firm more at higher quality levels. Consequently, when a firm decides how much to invest in order to improve product quality, it has to account for its future expected quality disclosure costs. These future information disclosure investments act as a hidden quality production cost at the stage of product design and when taken into account, lead to lower optimal quality, compared with the quality that a firm would have chosen under a perfect information regime.

Figure 7 explains how quality production in our model differs from classical quality unraveling, where firms invest in quality disclosure only above a certain quality threshold. The figure shows the marginal benefit and the marginal cost of quality under perfect information and under uncertainty, where marginal benefit is defined simply as marginal profits minus the marginal quality disclosure cost, and are derived by differentiating $p_{i}^{* 2} / t-s_{i}$ (from Equation 3) and quality investment cost, with respect to quality. Obviously, for every firm, equilibrium quality production is determined by the point where the marginal benefit of an additional quality increase matches the marginal quality production cost. Under classical quality unraveling, firms disclose quality only above a threshold $\tilde{q}$. Thus, on the left graph of Figure 7, the marginal benefit of increasing quality at any quality level below the disclosure threshold $\tilde{q}$, is zero, since quality below the threshold will not be disclosed 
and any quality improvement will go undetected with buyers assuming the worst possible product quality. However, the marginal benefit of increasing quality, when the quality is above the disclosure threshold $\tilde{q}$, is the same as the perfect information case, as quality will always be disclosed above the threshold. Therefore, with classical quality unraveling, optimal quality is either at its minimum level, or it is the same as the quality under perfect information, depending on whether or not the marginal cost curve meets the marginal benefit curve above the threshold.

In the current model, the marginal benefit of increasing quality lies below the marginal benefit under perfect information and non-zero disclosure probability, as we have seen in the previous section that any quality increase also increases the chances that a quality disclosure cost will be incurred. Therefore, compared to the perfect information case, our model predicts that firms will produce lower quality levels under uncertainty, as shown by the arrow on the right of Figure 7 .

An example showing firms investing less in quality under uncertainty, concerns hygiene in the Los Angeles restaurant market, and has been documented in (Jin and Leslie 2003). Prior to 1998, restaurants were not required to disclose their hygiene inspection results or to use any particular format when doing so. In 1998 a standardized report card was introduced that made reporting of hygiene inspections easily understood and comparable across all restaurants in all L.A. county cities. Each county city was then left to decide on whether or not to force their restaurants to prominently display these report cards. For cities that passed mandatory disclosure ordinances, the result was a transition to a perfect information regime, since any quality disclosure costs become sunk as mandatory. For cities that allowed for voluntary disclosure of health reports, the result was a reduction of the quality disclosure cost, since standardization had dramatically reduced the cost of explaining to consumers what the hygiene level of a restaurant was, compared with other restaurants in the area. This is equivalent to an upwards shift of the marginal benefit curve in the right hand side of Figure 7, very close to the perfect information marginal curve, which should also lead to an increase in quality (recall that disclosure costs are included in the marginal benefit). Indeed, Jin \& Leslie documented the subsequent increase in the hygiene levels on both mandatory and voluntary disclosure cities, as captured by increasing inspection scores, and also by the reduction of food-related hospital admissions in L.A. county ${ }^{14}$.

The managerial implication for our stylized example of the printer manufacturers in the Introduction, is that the firms must include the cost of future information disclosure in their quality production Return on Investment' (ROI) calculations, alongside items such as materials, Quality Assurance, and new feature design and development costs. Higher quality levels increase the probability that the firms will also need a quality disclosure investment. In other words, quality is

${ }^{14}$ The authors carefully excluded many potential alternative explanations, such as consumer sorting (consumers avoiding food-related poisoning by shifting to more hygienic restaurants). 
more expensive than it appears, due to consumer uncertainty. For example, substantial investments in the quality of future photo printer models, makes it more likely that the manufacturers will also need to invest to reduce consumer uncertainty about the printers' quality-related attributes. Quality improvements in photo printing may increase the chance that the manufacturer will have to provide detailed information about printer performance, such as accuracy of color rendition, or print longevity, for different ink-paper combinations. The manufacturer may have to work with retailers and distributors to provide output samples that demanding buyers will want to examine from up-close. The larger the quality improvements under consideration, the larger the disclosure cost that must be accounted for in the ROI calculations of the firms. If the printer manufacturers fail to take this cost into account, they would be overnivesting in product quality.

\subsection{Impact of Ambient Information on Firm's Information Investments}

Proposition 3. For firms with non-zero probability of disclosure, $\operatorname{Pr}_{i}\left(q_{i}\right)$ increases with $\alpha$.

Proof: $\quad$ Follows directly from Lemma 5, in the Appendix.

As with Proposition 1, Proposition 3 is also true for target product quality $q_{r i}$ (the probability of disclosure for a given level of quality investment decreases as $\alpha$ decreases), since expected actual product quality cannot decrease as target product quality increases. And as with Proposition 1, Proposition 3 is true with heterogeneous sellers, that differ in their cost of quality production $k$ and/or quality disclosure $c$ (see Appendix B and the Online Appendix).

The intuition is as follows. Firms' investments to reduce consumer uncertainty depend on the amount of ambient information available in the market. Infomediaries, consumer reviews, press coverage, and other third party sources of product information contribute to consumer informedness, often allowing firms to free ride and forgo their own information disclosure investments. However, as infomediaries provide more and more information, the sizes of uncertainty intervals that consumers can assign to different products reduces, and the potential for consumers to discount the quality of a seller who does not disclose diminishes, making non-disclosure less costly.

Google appears to have used information availability by third-parties, to reduce its own information disclosure costs. In 2003 the company created a community (Google Forums) where its customers could answer each other's questions about the company's AdWords product. This allowed Google to forgo the ongoing investment that would be required to fully inform the hundreds of thousands of customers on product features and use (Levy 2011). Today, Google Product Forums have been expanded to include all of the company's products.

Mathematically, the probability that a firm will disclose decreases, as quality uncertainty decreases. On the left side of Figure 8 we plot the (ex-ante) probability that a firm will invest in 

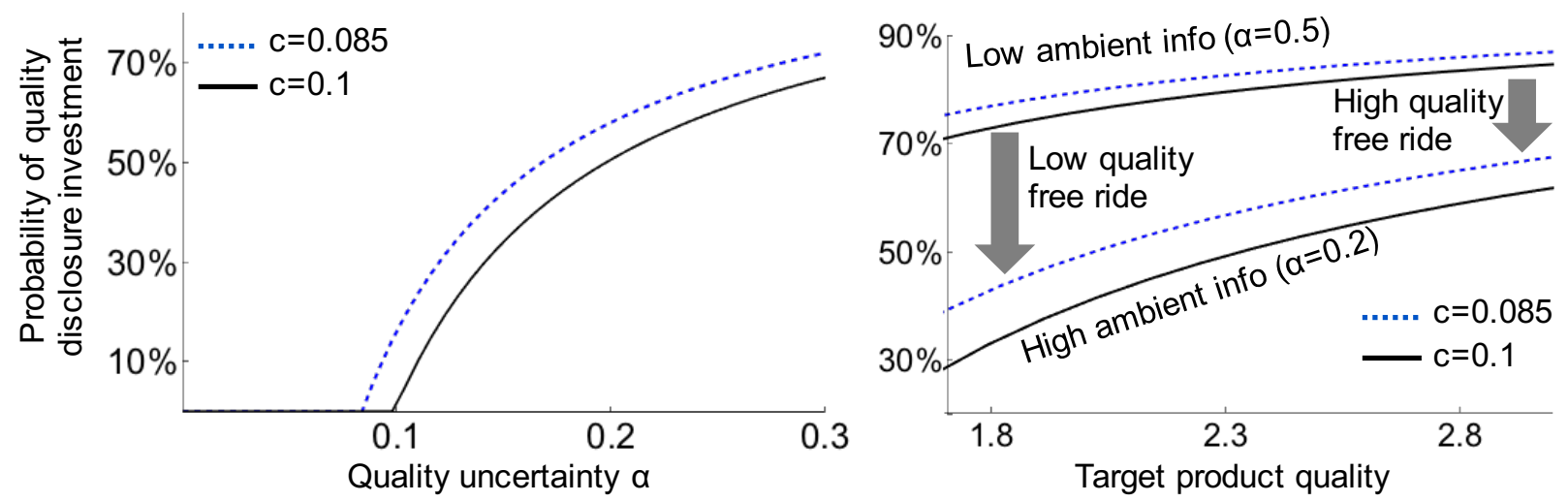

Figure 8 Ex-ante probability of quality disclosure investments as a function of quality uncertainty (left), and as a function of target seller qualities (right). Parameter values used are $N=3$ (which implies $b=0.8$ ),

$$
k=0.9, t=40, \theta=8, r=1.5
$$

information disclosure, as given in Theorem 1 and Lemmata 5 and 6 . No firm discloses when $\alpha$ is below a certain threshold relative to the quality disclosure cost, given in Lemma 6 .

Further, our model shows that the opportunity for firms to free ride on ambient information and forgo their own information disclosure investments is relatively greater for lower quality sellers. This is depicted on the right side of Figure 8, where we can see that as we increase the amount of ambient information in the market ( $\alpha$ reduces from 0.5 to 0.2 ) the (ex-ante) probability of a disclosure investment decreases, but more so for lower quality sellers. In other words, it is easier for lower quality sellers to free ride on third party information. Formally:

Proposition 4. The reduction in the sellers' (ex-ante) probability of quality disclosure as $\alpha$ decreases, is greater (in absolute value) at lower product qualities. Mathematically, let $\operatorname{Pr}_{i}\left(q_{i}, \alpha\right)$ be the probability that Seller $\mathrm{S}_{\mathrm{i}}$ will disclose, given quality $q_{i}$ and quality uncertainty $\alpha$, and let $x$ be a positive constant. Then $\operatorname{Pr}_{i}\left(q_{i}, \alpha\right)-\operatorname{Pr}_{i}\left(q_{i}, \alpha-x\right)$ decreases as $q_{i}$ increases.

Proof: From Lemma 5 in the Appendix, and also using Lemma 1, it can easily be shown by differentiation that at all product quality levels the derivative of the probability of disclosure with respect to product quality, decreases as $\alpha$ increases. Proposition 4 is now implied, as the probability of disclosure as a function of quality will always be steeper at lower $\alpha$.

As with Propositions 1 and 3, Proposition 4 is true with heterogeneous sellers, that differ in their cost of quality production $k$ and/or quality disclosure $c$ (see Appendix B and the Online Appendix).

The intuition behind this result is that any increase in quality reduces a firm's disclosure threshold inside its quality uncertainty interval. When the uncertainty interval is relatively small (high ambient information) even a small decrease in the position of the disclosure threshold can significantly affect the probability that a firm's quality will be below (or above) the threshold. Thus, the 


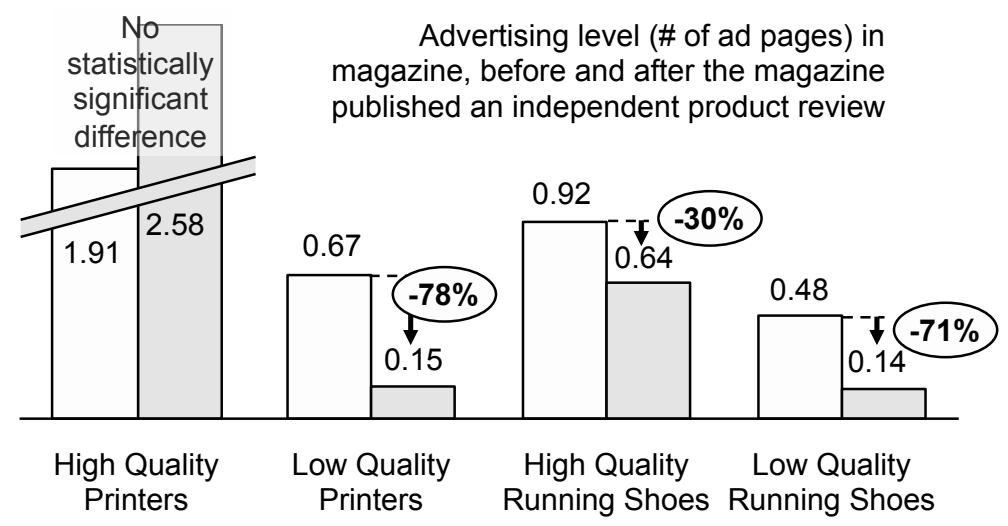

Figure 9 Impact of 3rd party disclosures to firms' own disclosure investments (Chen and Xie 2005)

probability of a disclosure investment becomes more sensitive on quality when $\alpha$ is low, as can be seen on the right side of Figure 8 where the bottom pair of lines is steeper. But, obviously, this means that the two pairs of lines should converge towards higher qualities, which means that free riding on ambient information should be less pronounced in higher qualities.

The managerial implication is that firms - especially those with lower quality products - that plan information disclosure investments, should account for ambient information availability and be aware of opportunities to free ride. This was nicely demonstrated by Chen and Xie (2005) who looked at how competing firms adjust their advertising as a response to an independent product review published in a magazine (see Figure 9). They observed reviews that discuss product quality and end in a recommendation (or not). As per our analysis, we would expect all firms to respond to a third party review by reducing the amount of information they disclose. Further, lower quality firms should reduce their disclosure spend, more than higher quality firms. This is what Chen \& Xie found. Higher quality printers did not significantly change their advertising spend, while lower quality printers did. Lower quality running shoes reduced their advertising spend, as a response to a product review, by $71 \%$, compared to $30 \%$ reduction for their high quality competitors.

While this example focused on third-party intermediaries, Proposition 4 and the associated discussion is equally applicable to other ambient information sources besides infomediaries (e.g. consumer reviews).

\subsection{Impact of Ambient Information on Quality}

Proposition 5. Large enough improvements in ambient information availability improve equilibrium quality. However, smaller improvements in information availability may reduce equilibrium quality.

Proof: Follows directly from Lemma 8 in the Appendix. Also see the left hand side of Figure 10 
In the case of heterogeneous sellers, Proposition 5 should be viewed as referring to the average prevailing quality in the market, and may not hold for each seller individually (see Appendix B and the Online Appendix).

Proposition 5 provides more information than Proposition 2 on the relationship between equilibrium quality and consumer uncertainty. It says that we do not need to obtain perfect information availability for equilibrium quality to improve. Going back to the example of Jin and Leslie (2003), we see that we do not need to go from a restaurant market with no hygiene information to a market with perfect hygiene information for hygiene levels to improve. As long as the improvement in ambient information is sufficient, sellers will improve their quality. This is consistent with the generally accepted view among practitioners that the dramatic improvements in consumer information availability due to third party infomediaries push sellers to improve their quality, as quality shortcomings are more likely to be exposed ${ }^{15}$.

However, if ambient information availability is low and improvements are not large enough, equilibrium quality reduces (see Arrow A in Fig 10) as firms compete less in quality.

The intuition ${ }^{16}$ builds upon the fact that with improved information, the probability of disclosure becomes more sensitive to quality, that is, with improved information even small changes in quality may significantly increase the probability of a future disclosure investment. This is what the right hand side of Figure 8 shows: the $\alpha=0.2$ lines are steeper than the $\alpha=0.5$ lines, and this is also what Proposition 4 says. The above immediately implies that firms will compete less in quality. This is because with improved information, any quality increase will create larger future disclosure costs, so that a quality increase becomes less desirable, and sellers will compete less intensely in quality, exactly as Proposition 5 states and Arrow A in Figure 10 shows.

A simplified arithmetic example is as follows. Imagine that the cost of a quality disclosure investment is 5 , and that, other things equal, a quality increase of 1 unit increases future expected revenue by 6 , net of quality production cost.

If information availability is low, the probability of disclosure may be high, assume it is $50 \%$. Also assume that the quality increase of 1 unit modestly increases the probability of a future disclosure from $50 \%$ to $70 \%$. Thus the firm that improves quality by 1 unit, other things equal, increases future profit by $6-0.2 \times 5=5$. That is, the quality improvement increases expected revenue by 6 units, but increases expected cost by 1 unit from the increase in the disclosure probability.

\footnotetext{
${ }^{15}$ In practice, teasing out the effects of information on quality is not always easy (Anderson and Magruder 2012).

16 The mechanism has many similarities with the mechanism of Dranove and Satterthwaite (2003) where improved price information leads to less intense quality competition (quality improvements become less attractive to the firms), and more intense price competition, so that firms reduce their quality. In our model, it is improved quality information that leads to less intense quality competition.
} 

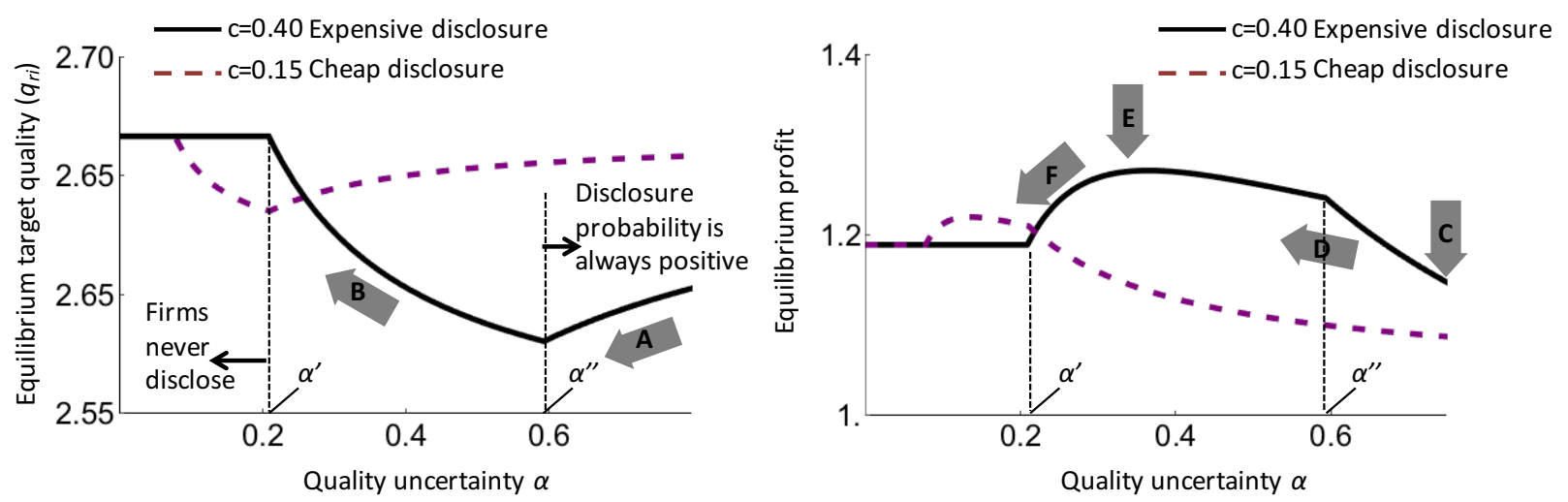

Figure 10 Equilibrium quality (left, given in Theorem 1) and expected equilibrium profit (right, derived in Lemma EC.1 in the Online Appendix) as a function of quality uncertainty. Parameter values used are

$$
N=3, k=1, t=40, \theta=10, r=1.5
$$

The same firm, under higher information availability, would have a lower probability of disclosure, i.e., the firm would be more likely to free-ride. Assume that the probability of disclosure is $20 \%$. But now the increase in quality by 1 unit would increase the probability of a future disclosure significantly, for example from $20 \%$ to $60 \%$ (probability of disclosure becomes more sensitive on quality, with improved information). The increase in future profit is now $6-0.4 \times 5=4$.

We see that quality improvements are less attractive to the seller when ambient information availability is high, so the seller will tend to compete less intensely in quality, which, as expected, leads to lower equilibrium quality levels.

However, when ambient information improves to the point where some sellers, depending on their quality realization, no longer wish to improve upon the information made available by infomediaries (this happens below $\alpha^{\prime \prime}$ shown in Figure 10 and derived in Lemma 6) disclosure probability begins to depend less on uncertainty, and quality improvements begin to become more attractive to the sellers (Arrow B in Figure 10). When ambient information improves below $\alpha^{\prime}$, sellers always withhold disclosure, and quality no longer depends on uncertainty $\alpha$, because disclosure probability (at zero) is no longer sensitive to quality. Profits are as elastic on quality as they are under perfect product information.

Consider again the stylized example of the printer manufacturers. The firms wish to know how the slowly changing information landscape affects how much they should invest in future quality improvements. Our model predicts that, if uncertainty is high and the improvements in overall information availability are small, quality investments become less attractive for competing firms as each quality improvement creates higher future disclosure costs. Then, the firms' best competitive response is to decrease product quality investments. However, in the long term, as long as the improvements in information availability continue, buyers will begin to depend more and more on 
infomediaries and other ambient sources for their information needs. Then, quality improvements become more attractive and the two competitors will need to start increasing their investments in printer quality. Given the significant increase in product information availability in recent years made possible by consumer reviews, third-party infomediaries and search tools, our model suggests that its net impact will be an increase in investments in product quality.

\subsection{Impact on Seller Profitability}

The right side of Figure 10 shows how ambient information and information disclosure costs impact firm profitability. Under very high quality uncertainty, firms almost always disclose (see Figure 8), and the market resembles a market of perfect information with firms always incurring the disclosure cost $c$. Consequently, under high quality uncertainty $\alpha$, equilibrium profit approaches profit under perfect quality information minus $c$ (see Arrow C). As $\alpha$ decreases, firms invest less in quality (Arrow A) and firms save both on quality production and on expected information investment cost (disclosure probability reduces) so that profits begin to increase (Arrow D) and can exceed profits under perfect information. Arrow E shows that maximum firm profitability is obtained when $\alpha$ is such that only some of the firms invest in quality disclosure, but the probability of disclosure is not yet zero. This is the point that balances low investments in quality (they are minimum at point $\alpha^{\prime \prime}$ ) with low investments in quality disclosure (they become zero below $\alpha^{\prime}$ ). As we decrease ambient information even further (Arrow F), the expected savings in disclosure costs are not enough to counteract increased quality production costs and profitability begins to decrease again. Note that profitability for $0<\alpha<\alpha^{\prime}$ is still slightly above the level obtained at $\alpha=0$ (the fact that the profit line in Figure 10 increases for low $\alpha$ is hard to discern because the increase is only slight), because of a utility transfer from buyers to sellers due to uncertainty. This is shown in Lemma EC.1 in the Online Appendix.

\section{Concluding Remarks}

In this paper, we investigated an integrated process of product design and product information investments, and argued that both decisions are influenced by each other and by the availability of ambient market information - information which consumers can easily acquire from other sources. Specifically, we analyzed the first game theoretic model of a competitive market, where product design and product information investments are endogenous decision variables, affected by information made available by third parties.

The thread that connects our findings is that information disclosure strategies must be considered alongside quality investment decisions in an integrated process. To maximize profit, managers must consider the nuanced ways in which buyers evaluate quality in markets with inherent uncertainty. In particular, our model indicates that buyers discount the quality of non-disclosing high quality 
firms more so than the quality of non-disclosing low quality firms. There are three managerial implications that emerge from our study.

First, we showed that, other things equal, quality investment under uncertainty never exceeds the level of quality investment under perfect information. Thus, forward-looking should be careful to give due weight to the costs of quality improvement, which are magnified in the presence of uncertainty, and avoid over-investing in quality.

Second, we showed that firms can take advantage of information that third parties provide, and avoid their own information disclosure investments. The opportunity to free ride is even greater for lower quality firms. Managers should consider whether the information that buyers can receive from third parties is already sufficient, so that they can forgo costly information investments. Of course, this largely depends on the environment, but as third party infomediaries proliferate, this advice is increasingly relevant. However, managers of firms with higher quality products should be more careful when avoiding disclosure investments and relying instead on third party infomediaries: buyers are shown to be more willing to punish complacency at the higher-ends of product ranges.

Finally, we showed that the intuitive argument that firms must improve their product quality when overall information availability in the market improves, only holds when the improvement is significant. If third party infomediaries do not significantly improve information availability in their market, the firms' may consider reducing their quality, as the optimal response. Managers that consider quality selection and quality disclosure planning as an integrated process, may not only avoid over-investing in quality, but also spot opportunities to reduce quality production costs.

We conclude with some directions for future work. Our model captures interaction between sellers and buyers in the presence of ambient information through infomediaries or social interaction among consumers. Presently, we have assumed that this ambient information is an exogenous characteristic of the market. An interesting extension of our work would be to incorporate the role of infomediaries as strategic players in the game. Further, after demonstrating that product design and information disclosure investments should be treated as an integrated process and should account for information made available by third parties, we must naturally turn our attention to a detailed empirical evidence for the theory. Indeed, this is necessary to validate our theory, enrich our recommendations, and make them more actionable and practical.

\section{Appendix A: Symbols used in notation}

\begin{tabular}{|c|c|}
\hline Symbol & Definition \\
\hline \multicolumn{2}{|c|}{ Decision Variables } \\
\hline$q_{r i}$ & Seller $\mathrm{S}_{\mathrm{i}}$ 's target quality \\
\hline$p_{i}$ & Seller $S_{i}$ 's product price \\
\hline
\end{tabular}




\begin{tabular}{|c|c|}
\hline Symbol & Definition \\
\hline$*$ & The starred version of each variable (as in $p_{i}^{*}$ ), denotes its value in equilibrium \\
\hline$s_{i}$ & Seller $\mathrm{S}_{\mathrm{i}}$ 's disclosure investment $s_{i} \in\{0, c\}$ \\
\hline \multicolumn{2}{|l|}{ Model Parameters } \\
\hline$N$ & Number of sellers in the market \\
\hline$v$ & Buyer utility for product of zero quality located at his most preferred type \\
\hline$q_{i}$ & Seller $\mathrm{S}_{\mathrm{i}}$ 's quality. The target quality $q_{r i}$ plus some noise parameter $\epsilon: q_{i}=q_{r i}+\epsilon$ \\
\hline$r$ & The error term $\epsilon$ (which affects $\left.q_{i}\right)$ is uniformly distributed in $[-r, r]$ \\
\hline$\overline{q_{i}}, E\left(\overline{q_{i}}\right)$ & $\begin{array}{l}\text { Random variable that corresponds to } q_{i} \text { under imperfect information, and its } \\
\text { expected value }\end{array}$ \\
\hline$\left[q_{i A}, q_{i B}\right]$ & Quality uncertainty interval of Seller $S_{i}$ \\
\hline$c$ & Cost for disclosing quality \\
\hline$\theta, t$ & The intensity of consumer preference for quality and type, respectively \\
\hline$C\left(q_{i}\right), k$ & $C\left(q_{i}\right)$ is the quality production cost and equals: $C\left(q_{i}\right)=k \cdot q_{i}^{2} / 2$ \\
\hline \multicolumn{2}{|l|}{ Derived Values } \\
\hline$\alpha$ & Size of the quality uncertainty interval. It equals $q_{i B}-q_{i A}$ \\
\hline$z_{i}$ & Most preferred location of buyer who is indifferent between Sellers $S_{i}$ and $S_{i+1}$ \\
\hline q & Vector with $N$ elements, where element $i$ is $E\left(\overline{q_{i}}\right)$ \\
\hline$\tilde{q}_{i} \underline{q_{i}}$ & $\tilde{q}_{i}$ is the value of $q_{i}$, above which quality is disclosed, and $\underline{q_{i}}$ is $E\left(\overline{q_{i}} \mid \overline{q_{i}}<\tilde{q}_{i}\right)$ \\
\hline$\delta_{i}$ & $\delta_{i}=\tilde{q}_{i}-\underline{q_{i}}$. Equals half the disclosure range \\
\hline$R_{i}, D_{i}, \Pi_{i}$ & Seller $\mathrm{S}_{\mathrm{i}}$ 's revenue, unit demand, and profit, respectively \\
\hline $\mathbf{p}$ & Vector of prices for all sellers \\
\hline $\mathbf{A}, \mathbf{A}^{-1}$ & $\begin{array}{l}\text { Symmetric circulant matrix } \mathbf{A} \text {, and its inverse. } A[i, i]=1, A[i+1, i]=-1 / 4 \text { and } \\
\text { zeros elsewhere }\end{array}$ \\
\hline $\mathbf{H}$ & Matrix $\mathbf{H}=\mathbf{A}-\mathbf{I} / 2$. Used for notational convenience \\
\hline$b_{i}, b$ & $b_{i}$ is element of the diagonal of $\mathbf{A}^{-1}$ at distance $i$ from main diagonal; $b$ is $b_{0}-b_{1}$ \\
\hline e & Vector defined as $\mathbf{e}=t / 2 N \cdot \mathbf{1}+\theta \cdot \mathbf{H} \cdot \mathbf{q}$. Used for notational convenience \\
\hline $\operatorname{Pr}_{i}(\cdot)$ & $\begin{array}{l}\text { The probability that Seller } S_{i} \text { will invest in quality disclosure, when uncertainty } \\
\text { intervals are not yet known }\end{array}$ \\
\hline$c^{\prime}, \alpha^{\prime}$ & $\begin{array}{l}\text { When } c>c^{\prime} \text {, or when } \alpha<\alpha^{\prime} \text { sellers always withhold information regardless of } \\
\text { their quality realization }\end{array}$ \\
\hline$c^{\prime \prime}, \alpha^{\prime \prime}$ & $\begin{array}{l}\text { When } c<c^{\prime \prime} \text {, or when } \alpha>\alpha^{\prime \prime} \text { sellers have non-zero disclosure probability } \\
\text { regardless of their quality realization. }\end{array}$ \\
\hline
\end{tabular}

\section{Appendix B: Heterogeneous sellers}

In our model, sellers are identical, except for their placement in the taste space. Our results about quality disclosure (Propositions 1, 3, and 4) still hold even for heterogeneous sellers that differ in their costs of quality production and/or quality disclosure. Proofs for the validity of these propositions under seller heterogeneity are provided in the Online Appendix. The proofs rely on the fact that the last two game stages, on which 

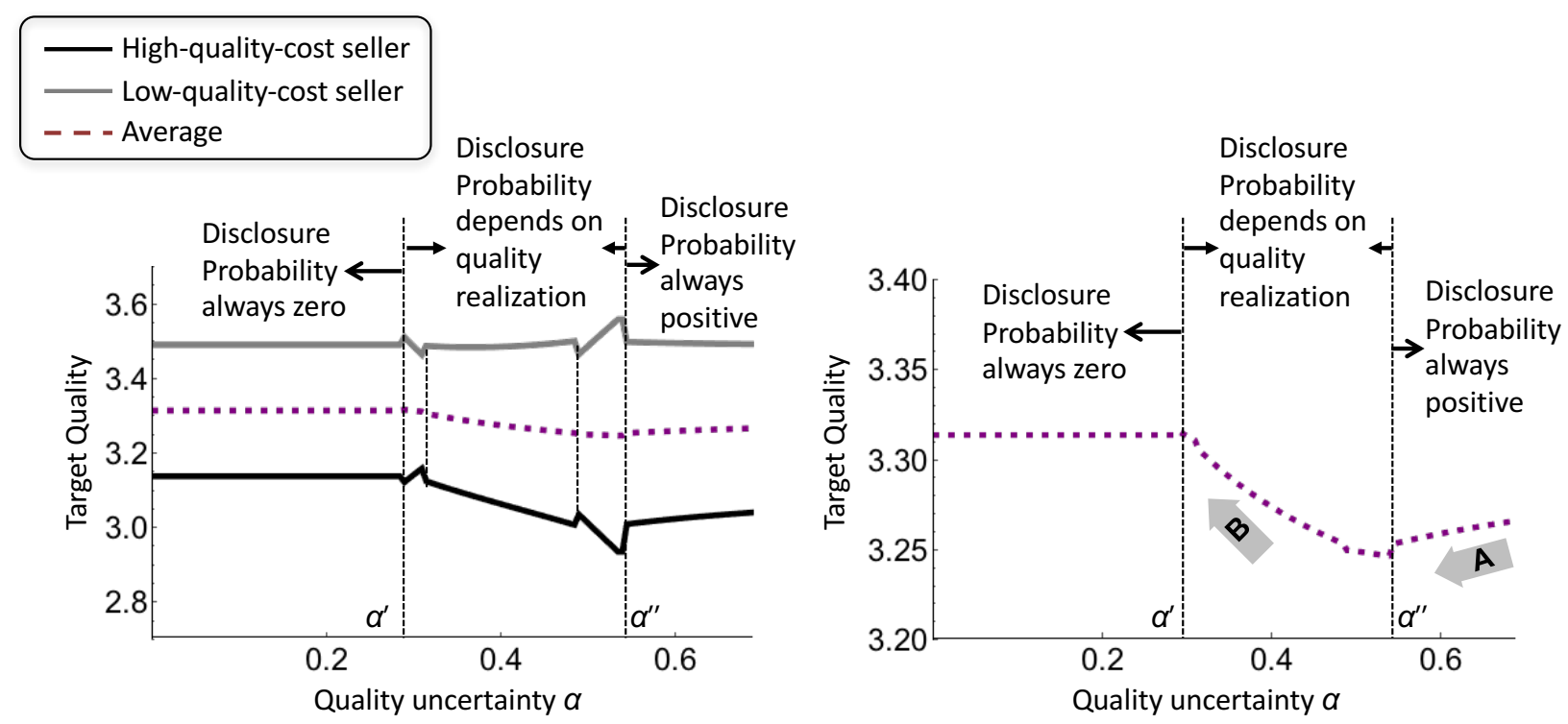

Figure 11 Equilibrium quality as a function of quality uncertainty in a duopoly where the sellers differ in their costs of quality production. We label the seller with the lower cost of quality production as "Low-quality-cost seller", and its competitor as the "High-quality-cost seller". Parameter values used are

$$
N=2, k_{1}=0.8, k_{2}=0.81, c_{1}=c_{2}=0.5, t=40, \theta=8, r=2
$$

Proposisions 1,3 , and 4 depend, take target quality $q_{r i}$ and actual quality $q_{i}$ as given, without making any assumptions about how the quality level came to be.

However, without identical sellers, we can find numerical counter-examples to Propositions 2 and 5 (we can no longer derive closed form solutions for seller qualities across all parameter ranges). For example, Figure 11 shows that it is no longer true that no sellers would choose higher quality under uncertainty, compared to the perfect information case.

This is expected. Revenue cannot be less elastic in quality for all sellers under imperfect information. If a seller's competitors' have different ex-ante probability of quality disclosure, then this affects how elastic the seller's revenue is on target quality. With heterogeneity, for roughly half the sellers we should expect that the difference in disclosure probability pushes elasticity of revenue on target quality to be lower under uncertainty (e.g., the sellers with lower than average probability of disclosure), that is, to amplify the impact described in Proposition 2 and for the other half sellers that the difference in disclosure probability should push in the opposite direction and counteract the impact described in Proposition 2. Depending on the degree of seller heterogeneity, we should expect to find sellers with higher target quality under uncertainty.

Nevertheless, this does not imply that the driving forces behind Propositions 2 and 5 are no longer valid: overall competition for quality is indeed less intense under uncertainty, other things equal, and we should expect to observe so on average. For example in Figure 11, we depict two sellers that differ in their costs of quality production. While the low-disclosure-cost seller can have higher quality under uncertainty, compared to the perfect information case $(\alpha=0)$, the average target quality behaves similarly to Figure 10 where the sellers where identical. 
In the Online Appendix, we study the case of duopoly competition with heterogeneous sellers in more detail, including sellers that also differ in their costs of quality disclosure. In summary, our paper's results about quality disclosure do not depend on seller homogeneity (Propositions 1, 3, and 4), and the results about quality production describe forces that are present even in the case where the sellers are heterogeneous. Then, Propositions 2 and 5 describe how the average quality depends on quality uncertainty, rather than the quality of each and every seller in the market.

\section{Appendix C: Proofs and derivations}

\section{C.1. Stages 3 and 2}

The Pricing Stage of the game (Stage 3) and the Information Disclosure Investment Stage (Stage 2) have already been analyzed in Section 3.2.

\section{C.2. The Quality Choice Stage (Stage 1)}

In this stage, firms anticipate that later, in the information disclosure stage, the probability that they will disclose will increase with their quality choice at the present stage. Firms further anticipate that, in the final game stage, prices will follow the non-cooperative equilibrium given in by Equation 6 .

Before we can calculate how sellers choose qualities, we must first calculate the probability that sellers assign to the event that they will have to incur a disclosure cost in the future. Specifically, we need to calculate the quantity $\delta_{i}$ that appears in Equation 8: $\operatorname{Pr}_{i}\left(q_{i}\right)=1-2 \delta_{i} / \alpha$. To do that, we must first know the distribution $f_{q_{i}}^{\prime}$ of $E\left(\overline{q_{i}}\right)$, before the uncertainty intervals realize.

LEMMA 4. Before uncertainty intervals realize, $E\left(\overline{q_{i}}\right)$ is a random variable $E\left(\overline{q_{i}}\right)=q_{i}+\varphi$, with $\varphi$ a random variable with support $\left[-\delta_{i}, \delta_{i}\right]$ and $P D F f_{q_{i}}^{\prime}$ given by: $\operatorname{Pr}_{i}\left(q_{i}\right) \cdot \delta(\varphi)+\left(1-\operatorname{Pr}_{i}\left(q_{i}\right)\right) \cdot \frac{1}{2 \delta_{i}}$, where $\delta(\varphi)$ is Dirac's delta function. Furthermore, $f_{q_{i}}^{\prime}$ has the following properties:

$$
\int_{-\delta_{i}}^{\delta_{i}} \varphi \cdot f_{q_{i}}^{\prime}(\varphi) \cdot d \varphi=0, \quad \int_{-\delta_{i}}^{\delta_{i}} s \cdot f_{q_{i}}^{\prime}(\varphi) \cdot d \varphi=s, \quad \int_{-\delta_{i}}^{\delta_{i}} \varphi^{2} \cdot f_{q_{i}}^{\prime}(\varphi) \cdot d \varphi=\frac{\alpha^{2}\left(1-\operatorname{Pr}_{i}\left(q_{i}\right)\right)^{3}}{12}
$$

\section{Proof: Shown in the Online Appendix}

In equilibrium, all sellers choose their quality disclosure strategy according to Lemma 3 and Seller $S_{i}$ chooses his optimal quality disclosure threshold $\tilde{q}_{i}$, consistent with every other seller $\mathrm{S}_{\mathrm{j}}$ optimally choosing quality disclosure threshold $\tilde{q_{j}}$. The quantity $\delta_{i} \equiv \tilde{q}_{i}-\underline{q i}$ is given as a function of $q_{i}$ by: (see Online Appendix):

$$
\delta_{i}\left(q_{i}\right)=\min \left[\frac{2}{\theta \cdot b}\left(p_{i}^{*}\left(q_{i} \mid \forall j \neq i: E\left(\overline{q_{j}}\right)=q_{r j}\right)-\sqrt{p_{i}^{*}\left(q_{i} \mid \forall j \neq i: E\left(\overline{q_{j}}\right)=q_{r j}\right)^{2}-t \cdot c}\right), \alpha / 2\right]
$$

Buyers discount non-disclosing products by $\alpha / 2-\delta_{i}>0$, since buyers update their expectation for the product's expected quality from $q_{i A}+\alpha / 2$ to $q_{i A}+\delta_{i}$, as $\delta_{i}$ was defined to be $\delta_{i} \equiv \tilde{q}_{i}-\underline{q i}$.

Note that Seller $S_{i}$ 's equilibrium price in Equation 9, is the price that Seller $S_{i}$ would have chosen if for all other sellers $E\left(\overline{q_{j}}\right)$ exactly matched $q_{r j}$. In other words, the formula says that a seller who must choose his quality disclosure threshold $\tilde{q}_{i}$, optimizes by assuming that for every competitor $\mathrm{S}_{\mathrm{j}}, E\left(\overline{q_{j}}\right)$ will neither overestimate nor underestimate the competitor's target quality $q_{r j}$. For simplicity, the remaining of the article will somewhat abuse the notation and use $p_{i}^{*}\left(q_{i}\right)$ to mean: $p_{i}^{*}\left(E\left(\overline{q_{i}}\right)=q_{i} \mid \forall j \neq i: E\left(\overline{q_{j}}\right)=q_{r j}\right)$. 
We can now calculate the probability $\operatorname{Pr}_{i}\left(q_{i}\right)$ that Seller $S_{i}$ will disclose, given actual quality $q_{i}$, as well as the quality investment cost $c^{\prime}$ and quality uncertainty $\alpha^{\prime}$ beyond which sellers always withold disclosure, and the quality investment cost $c^{\prime \prime}$ and quality uncertainty $\alpha^{\prime \prime}$ beyond which sellers always have a positive probability of disclosure, regardless of the realization of their quality, given their quality target.

Lemma 5. $\operatorname{Pr}_{i}\left(q_{i}\right)=\max \left[0,1-\frac{4}{\theta \cdot b \cdot \alpha}\left(p_{i}^{*}\left(q_{i}\right)-\sqrt{p_{i}^{*}\left(q_{i}\right)^{2}-t \cdot c}\right)\right]$

Proof: $\quad$ The Lemma is proven by substituting $\delta$ in Equation 8 with its value from Equation 9.

Lemma 6. A seller with target quality $q_{r i}$ will never disclose when $c>c^{\prime}$, or when $\alpha<\alpha^{\prime}$, where $c^{\prime}$ and $\alpha^{\prime}$ are obtained by solving for $c$ and for $\alpha$ the equation $\int_{-r}^{r} \frac{P r_{i}\left(q_{r i}+\epsilon\right)}{2 r} d \epsilon=0$, or equivalently, the equation $1-\frac{4}{\theta \cdot b \cdot \alpha}\left(p_{i}^{*}\left(q_{r i}\right)+\frac{r \cdot \theta \cdot b}{2}-\sqrt{\left(p_{i}^{*}\left(q_{r i}\right)+\frac{r \cdot \theta \cdot b}{2}\right)^{2}-t \cdot c}\right)=0$. Also, a seller with target quality $q_{r i}$ will always disclose with positive probability when $c<c^{\prime \prime}$, or when $\alpha>\alpha^{\prime \prime}$, where $c^{\prime \prime}$ and $\alpha^{\prime \prime}$ are obtained by solving for $c$ and for $\alpha$ the equation $1-\frac{4}{\theta \cdot b \cdot \alpha}\left(p_{i}^{*}\left(q_{r i}\right)-\frac{r \cdot \theta \cdot b}{2}-\sqrt{\left(p_{i}^{*}\left(q_{r i}\right)-\frac{r \cdot \theta \cdot b}{2}\right)^{2}-t \cdot c}\right)=0$

Proof: Given that $\operatorname{Pr}_{i}\left(q_{r i}\right)$ is never less than zero (from Lemma 5), $\int_{-r}^{r} \frac{P r_{i}\left(q_{r i}+\epsilon\right)}{2 r} d \epsilon=0$ checks that the probability is zero throughout all possible realizations of actual product quality, given target product quality. Given that the probability increases with quality (Proposition 1), we can also obtain $c^{\prime}$ or $\alpha^{\prime}$ by solving for $c$ and $\alpha$ respectively the equation $\operatorname{Pr}_{i}\left(q_{r i}+r\right)=0$. Using Lemma 1 this equation becomes $\operatorname{Pr}_{i}\left(q_{r i}+r\right)=1-$ $\frac{4}{\theta \cdot b \cdot \alpha}\left(p_{i}^{*}\left(q_{r i}\right)+\frac{r \cdot \theta \cdot b}{2}-\sqrt{\left(p_{i}^{*}\left(q_{r i}\right)+\frac{r \cdot \theta \cdot b}{2}\right)^{2}-t \cdot c}\right)=0$. Similarly for $c^{\prime \prime}$ or $\alpha^{\prime \prime}$, where we solve for $\operatorname{Pr}_{i}\left(q_{r i}-r\right)=$ 0 .

Proposition 1 Let $\operatorname{Pr}_{i}\left(q_{i}\right)$ be the probability that Seller $\mathrm{S}_{\mathrm{i}}$ will disclose, given quality $q_{i}$. Then $\operatorname{Pr}_{i}\left(q_{i}\right)$ can only increase in $q_{i}$. Moreover, the relationship is continuous.

Proof: The second part of the Proposition, that the relationship between $\operatorname{Pr}_{i}\left(q_{i}\right)$ and $q_{i}$ is continuous, is easily verifiable by the analytical description of the probability in Lemma 5 . The first part of the proposition, that $\operatorname{Pr}_{i}\left(q_{i}\right)$ can only increase in $q_{i}$, can be proven either by starting from Equation 9 , or by starting from Lemma 5. In the first approach, as long as $\delta_{i}$ has not reached its maximum value $\alpha / 2$, it decreases in equilibrium price $p_{i}^{*}: d \delta_{i} / d p_{i}^{*}=\cdots=\frac{2}{\theta b}\left(1-p_{i}^{*} / \sqrt{p_{i}^{* 2}-t \cdot c}\right)<0$. Thus $\frac{d \delta_{i}}{d E\left(\overline{q_{i}}\right)}=\left(\frac{d \delta_{i}}{d p_{i}^{*}}\right) \cdot\left(\frac{d p_{i}^{*}}{d E\left(\overline{q_{i}}\right)}\right)=\frac{d \delta_{i}}{d p_{i}^{*}} \cdot \frac{\theta b}{2}<0$. Further, given $q_{i A}, \delta_{i}$ is $1-1$ with $\tilde{q}_{i}$ and it is also true that $d E\left(\overline{q_{i}}\right) / d q_{i}>0$. Thus, we obtain $d \delta_{i} / d E\left(\overline{q_{i}}\right)<$ $0 \Longleftrightarrow d\left(\tilde{q}_{i}-q_{i A}\right) / d E\left(\overline{q_{i}}\right)<0 \Longleftrightarrow d\left(\tilde{q}_{i}-q_{i A}\right) / d q_{i}<0$. Fixing $q_{i A}$ also fixes $q_{i B}$, and so $d\left(q_{i B}-\tilde{q}_{i}\right) / d q_{i}>0$, so that $\operatorname{Prob}\left(q_{i}>\tilde{q}_{i}\right)$ is increasing in $q_{i}$. Also accounting for the fact that $\delta_{i}$ cannot exceed $\alpha / 2$ (or equivalently $\operatorname{Prob}\left(q_{i}>\tilde{q}_{i}\right) \geq 0$ ) we conclude that $\operatorname{Prob}\left(q_{i}>\tilde{q}_{i}\right)$ is non-decreasing in $q_{i}$. Thus, the probability of quality disclosure in Stage 2 can only increase with seller's quality $q_{i}$, which completes the proof.

The Proposition 1 is also true for target product quality $q_{r i}$ (the probability of disclosure can only increase with $q_{r i}$ ) since expected actual product quality cannot decrease as target product quality increases.

To calculate the equilibrium, only the conditional expected profit of Seller $\mathrm{S}_{\mathrm{i}}$ (which takes competitor choices as given) is required. Using Lemma 1 and Equations 3 and 6, conditional expected profit is ${ }^{17}$ :

${ }^{17}$ We assume that $r>>\alpha$ so that we can account for different realizations of the quality uncertainty interval by integrating in Equation 10 over $\int_{-\delta_{i}}^{\delta_{i}} f_{q_{i}}^{\prime}(\varphi) d \varphi$ everywhere, knowing that the value added by the part of the uncertainty interval that may fall above $q_{r i}+r$ or below $q_{r i}-r$ can be made as low as required, for sufficiently large $r$ or sufficiently small $\alpha$ (recall that $\delta_{i}$ is bound by $\alpha / 2$ ). In fact the expected profit obtained for $r>2 \alpha$ in Figure 10 yields equilibrium target qualities that are within $99.9 \%$ of the true value, even if we omit to integrate over $\int_{-\delta_{i}}^{\delta_{i}} f_{q_{i}}^{\prime}(\varphi) d \varphi$ in Equation 10 altogether (see Proof of Lemma 8). Thus in practice the requirement that $r>>\alpha$ is not necessary. 


$$
\begin{aligned}
& E\left(\Pi\left(q_{r i}\right)\right)= \\
& =E\left(\frac{\left.p_{i}^{*}\left(q_{i} \mid q_{r i}\right)\right)^{2}}{t}-\frac{k \cdot q_{r i}^{2}}{2}-c \cdot \operatorname{Pr}_{i}\left(q_{i} \mid q_{r i}\right)\right)=\int_{-r}^{r} \int_{-\delta_{i}}^{\delta_{i}}\left(\frac{p_{i}^{*}\left(q_{r i}+\epsilon+\varphi\right)^{2}}{t}-\frac{k \cdot q_{r i}^{2}}{2}-c \cdot \operatorname{Pr}_{i}\left(q_{r i}+\epsilon\right)\right) \cdot \frac{d \epsilon}{2 r} f_{q_{i}}^{\prime}(\varphi) d \varphi= \\
& =\int_{-r}^{r}\left(\int_{-\delta_{i}}^{\delta_{i}} \frac{\left(p_{i}^{*}\left(q_{r i}+\epsilon\right)+\frac{\theta \cdot b \cdot \varphi}{2}\right)^{2}}{t} f_{q_{i}}^{\prime}(\varphi) d \varphi-\frac{k \cdot q_{r i}^{2}}{2}-c \cdot \operatorname{Pr}_{i}\left(q_{r i}+\epsilon\right)\right) \cdot \frac{1}{2 r} d \epsilon= \\
& =\int_{-r}^{r}\left(\frac{p_{i}^{*}\left(q_{r i}+\epsilon\right)^{2}}{t}+0+\int_{-\delta_{i}}^{\delta_{i}} \frac{(\theta \cdot b \cdot \varphi)^{2}}{4 t} f_{q_{i}}^{\prime}(\varphi) d \varphi-\frac{k \cdot q_{r i}^{2}}{2}-c \cdot \operatorname{Pr}_{i}\left(q_{r i}+\epsilon\right)\right) \cdot \frac{1}{2 r} d \epsilon=\ldots= \\
& =\int_{-r}^{r}\left(\frac{\left(p_{i}^{*}\left(q_{r i}\right)+\frac{\theta \cdot b \cdot \epsilon}{2}\right)^{2}}{t}-\frac{k \cdot q_{r i}^{2}}{2}-c \cdot \operatorname{Pr}_{i}\left(q_{r i}+\epsilon\right)+\frac{\alpha^{2} \cdot b^{2} \cdot \theta^{2}\left(1-\operatorname{Pr}_{i}\left(q_{r i}+\epsilon\right)\right)^{3}}{48 t}\right) \cdot \frac{1}{2 r} d \epsilon \Longleftrightarrow \ldots \Longleftrightarrow \\
& E\left(\Pi\left(q_{r i}\right)\right)=\frac{p_{i}^{*}\left(q_{r i}\right)^{2}}{t}+\frac{\theta^{2} b^{2} r^{2}}{12 t}-\frac{k \cdot q_{r i}^{2}}{2}+\int_{-r}^{r}\left(\frac{\alpha^{2} \cdot b^{2} \cdot \theta^{2}\left(1-\operatorname{Pr}_{i}\left(q_{r i}+\epsilon\right)\right)^{3}}{48 t}-c \cdot \operatorname{Pr}_{i}\left(q_{r i}+\epsilon\right)\right) \cdot \frac{1}{2 r} d \epsilon \quad(10)
\end{aligned}
$$

We will also use the following Lemma which we prove in the Online Appendix:

Lemma 7. $q_{r i}^{*}=\arg \max _{q_{r i}} \Pi\left(q_{r i} \mid \forall j \neq i: E\left(\overline{q_{j}}\right)=q_{r j}\right)$

Using Lemma 7 and working with the competitors target qualities $q_{r j}$, instead of the random variables $\overline{q_{j}}$, and assuming that all vendors except vendor $\mathrm{S}_{\mathrm{i}}$ have chosen target qualities $q_{r j}=q, \forall j \neq i$, then from Equation 6 (see also Figure 3):

$$
\begin{array}{r}
p_{i}^{*}\left(q_{r i} \mid \forall j \neq i: E\left(\overline{q_{j}}\right)=q\right)=\sum_{j=-N / 2}^{N / 2}\left(b_{j} \frac{t}{2 N}\right)+\frac{b \cdot \theta}{2}\left(q_{r i}-q\right)=\frac{t}{2 N}\left(\sum_{j=-N / 2}^{N / 2} b_{j}\right)+\frac{b \cdot \theta}{2}\left(q_{r i}-q\right) \Longleftrightarrow \\
p_{i}^{*}\left(q_{r i} \mid \forall j \neq i: E\left(\overline{q_{j}}\right)=q\right)=\frac{t}{N}+\frac{b \cdot \theta}{2}\left(q_{r i}-q\right)
\end{array}
$$

because the sum of elements of any row of $\mathbf{A}^{-1}$ equals 2 .

Lemma 8.

$$
q_{r i}^{*}= \begin{cases}\frac{b \cdot \theta}{k \cdot N} & \text { if } c>c^{\prime} \\ \frac{b \cdot \theta}{k \cdot N}-A & \text { if } c^{\prime \prime}<c<c^{\prime} \\ \frac{b \cdot \theta}{k \cdot N}-B & \text { if } c<c^{\prime \prime}\end{cases}
$$

where $A$ is given by $A=\frac{192 N^{2} t B^{2}+384 N t^{2} B+256 t^{3}-32 N(N B+2 t)^{2} L 1-b^{3} N^{3}\left(\alpha^{3}-32 r^{3}\right) \theta^{3}-16 c N^{3} t(4 L 1+3 \alpha b \theta)}{96 \alpha k N^{3} t B}$, and $B$ is given by $B=\frac{\left(2 c N^{2} t+4 t^{2}+F^{2} N^{2}\right)(L 1-L 2)-4 N \cdot t \cdot F(L 1+L 2)+24 F t^{2}+2 F^{3} N^{2}}{3 \alpha k N^{2} t F}$, with $F=b \cdot r \cdot \theta, \quad L 1=$ $\sqrt{\left.(b \cdot r \cdot \theta+2 t / N)^{2}-4 c \cdot t\right)}, L 2=\sqrt{\left.(b \cdot r \cdot \theta-2 t / N)^{2}-4 c \cdot t\right)}$, and $c^{\prime}$ and $c^{\prime \prime}$ given in Lemma 6 .

Proof: Seller $\mathrm{S}_{\mathrm{i}}$ optimizes quality production when $\theta E\left(\Pi\left(q_{r i}\right)\right) / \theta q_{r i}=0$, where expected profit is given by Equation 10. Using Lemma 5, Equations 10 and 11, setting $q_{r i}=q$ and solving for $q$, we find the symmetric equilibrium in target qualities, to which every seller is responding optimally to all other sellers having chosen quality $q$ as their target quality.

There exist three different cases. If for all sellers $\int_{-r}^{r} \frac{c \cdot P r_{i}\left(q_{r i}+\epsilon\right)}{2 r} d \epsilon=0$ (which implies $c>c^{\prime}$ ) then, from Lemma 5, for all sellers $\operatorname{Pr}_{i}\left(q_{i}\right)=0$. Setting $q_{r i}=q$ in $\theta E\left(\Pi\left(q_{r i}\right)\right) / \theta q_{r i}=0$, and solving for $q$, we obtain $p_{i}^{*}=t / N$, and $q_{r i}=\frac{\theta \cdot b}{k \cdot N}$. If, $c<c^{\prime \prime}$, all sellers have non-zero disclosure probability and from Lemma 5 $\operatorname{Pr}_{i}\left(q_{i}\right)=1-\frac{4}{\theta \cdot b \cdot \alpha}\left(p_{i}^{*}\left(q_{i}\right)-\sqrt{p_{i}^{*}\left(q_{i}\right)^{2}-t \cdot c}\right)$. Then $q_{r i}=\frac{b \cdot \theta}{k \cdot N}-B$. 
For $c^{\prime \prime}<c<c^{\prime}$ the disclosure probability $\operatorname{Pr}_{i}\left(q_{r i}+\epsilon\right)$ that appears in Equation 10 is either $\operatorname{Pr}_{i}\left(q_{r i}+\epsilon\right)=0$ or $\operatorname{Pr}_{i}\left(q_{r i}+\epsilon\right)=1-\frac{4}{\theta \cdot b \cdot \alpha}\left(p_{i}\left(q_{r i}\right)+\frac{\theta \cdot b \cdot \epsilon}{2}-\sqrt{\left(p_{i}\left(q_{r i}\right)+\frac{\theta \cdot b \cdot \epsilon}{2}\right)^{2}-t \cdot c}\right)$, depending on the value of $\epsilon$. Solving $1-$ $\frac{4}{\theta \cdot b \cdot \alpha}\left(p_{i}\left(q_{r i}\right)+\frac{\theta \cdot b \cdot \epsilon}{2}-\sqrt{\left(p_{i}\left(q_{r i}\right)+\frac{\theta \cdot b \cdot \epsilon}{2}\right)^{2}-t \cdot c}\right)=0$ for $\epsilon$ we obtain $\epsilon=\frac{16 c \cdot t-8 \alpha \cdot b \cdot \theta \cdot p_{i}\left(q_{r i}\right)+\alpha^{2} b^{2} \theta^{2}}{4 \alpha b^{2} \theta^{2}}$. In Equation 10 we take the integral $\int_{-r}^{\frac{16 c \cdot t-8 \alpha \cdot b \cdot \theta \cdot p_{i}\left(q_{r i}\right)+\alpha^{2} b^{2} \theta^{2}}{4 \alpha b^{2} \theta^{2}}}$ using $\operatorname{Pr}_{i}\left(q_{r i}+\epsilon\right)=0$ and $\int_{\frac{16 c \cdot t-8 \alpha \cdot b \cdot \theta \cdot p_{i}\left(q_{r i}\right)+\alpha^{2} b^{2} \theta^{2}}{4 \alpha b^{2} \theta^{2}}}^{r}$ using $\operatorname{Pr}_{i}\left(q_{r i}+\epsilon\right)=1-\frac{4}{\theta \cdot b \cdot \alpha}\left(p_{i}\left(q_{r i}\right)+\frac{\theta \cdot b \cdot \epsilon}{2}-\sqrt{\left(p_{i}\left(q_{r i}\right)+\frac{\theta \cdot b \cdot \epsilon}{2}\right)^{2}-t \cdot c}\right)$. Setting $q_{r i}=q$ in $\theta E\left(\Pi\left(q_{r i}\right)\right) / \theta q_{r i}=0$, and solving for $q$, we obtain $\frac{b \cdot \theta}{k \cdot N}-A$.

This concludes the Proof.

THEOREM 1 The subgame-perfect equilibrium.

Proof: Combining Equations 6 and 9, and Lemma 8, we obtain Theorem 1. The value of $\varphi$ in the Theorem is obtained by calculating $2 \delta$ using Equation 9 and using the equilibrium values for all target qualities, and Lemma 1. The ex-ante expected price is calculated by integrating for all possible realizations of actual product qualities and quality uncertainty intervals.

\section{Acknowledgments}

The authors thank the Net Institute for generous support of our research. Further, we thank Nicholas Economides, Alex Miller, and anonymous reviewers for their valuable feedback.

\section{References}

Albano, Gian Luigi, Alessandro Lizzeri. 2001. Strategic certification and the provision of quality. International Economics Review 42(1).

Anderson, Michael, Jeremy Magruder. 2012. Learning from the crowd: Regression discontinuity estimates of the effects of an online review database. The Economic Journal 122(563) 957-989.

Bagnoli, Mark, Ted Bergstrom. 2005. Log-concave probability and its applications. Economic Theory 26(2) $445-469$.

Board, Oliver. 2009. Competition and disclosure. The Journal of Industrial Economics 57(1) 197-213.

Chang, Tung-Zong, Albert R. Wildt. 1994. Price, product information, and purchase intention: An empirical study. Journal of the Academy of Marketing Science 22(1) 16-27.

Chen, Yubo, Jinhong Xie. 2005. Third-party product review and firm marketing strategy. Marketing Science 24(2) 218-240.

Cheong, Insuk, Jeong-Yoo Kim. 2004. Costly information disclosure in oligopoly. The Journal of Industrial Economics 52(1) 121-132.

Crossley, Rob. 2010. Crytek and the shifting state of play. Develop Retreived from http://www.developonline.net.

Dranove, Kessler D. McClellan M., D., M. Satterthwaite. 2003. Is more information better? the effects of report cards on health care providers. Journal of Political Economy 111(3) 555-588. 
Dye, Ronald A. 1986. Proprietary and nonproprietary disclosures. Journal of Business 59(2) 331-366.

Dye, Ronald A., Sri S. Sridhar. 1995. Industry-wide disclosure dynamics. Journal of Accounting Research 33(1) 157-174.

Economides, Nicholas. 1989. Symmetric equilibrium existence and optimality in differentiated product markets. Journal of Economic Theory 47(1) 178-194.

Economides, Nicholas. 1993. Quality variations in the circular model of variety-differentiated products. Regional Science and Urban Economics 23(2) 235-257.

Farrell, Joseph. 1986. Voluntary Disclosure: Robustness of the Unraveling Result, and Comments on Its Importance. Lexington Books, 91-103.

Fishman, Michael J., Kathleen M. Hagerty. 2003. Mandatory vs voluntary disclosure in markets with informed and uninformed customers. The Journal of Law, Economics, \& Organization 19(1) 45-63.

Gabszewicz, J. Jaskold, J.-F. Thisse. 1979. Price competition, quality and income disparities. Journal of Economics Theory 20(3) 340-359.

Grossman, S. J., O. D. Hart. 1980. Disclosure laws and takeover bids. The Journal of Finance 35(2) 323-334.

Grossman, Sanford J. 1981. The informational role of warranties and private disclosure about product quality. Journal of Law and Economics 24(3) 461-489.

Hotz, V. Joseph, Mo Xiao. 2013. Strategic information disclosure: The case of multi-attribute products with heterogeneous consumers. Economic Inquiry 51(1) 865-881.

Jin, Ginger Zhe. 2005. Competition and disclosure incentives: an empirical study of hmos. RAND Journal of Economics 36(1) 93-112.

Jin, Ginger Zhe, Phillip Leslie. 2003. The effect of information on product quality: Evidence from restaurant hygiene grade cards. The Quarterly Journal of Economics 118(2) 409-451.

Jovanovic, Boyan. 1982. Truthful disclosure of information. Bell Journal of Economics 13(1) 36-44.

Koh, Noi Sian, Nan Hu, Eric K. Clemons. 2010. Do online reviews reflect a product's true perceived quality? an investigation of online movie reviews across cultures. Electronic Commerce Research and Applications 9(5) 374-385.

Levin, Dan, James Peck, LixinYe. 2009. Quality disclosure and competition. The Journal of Industrial Economics 57(1) 167-196.

Levy, S. 2011. In The Plex: How Google Thinks, Works, and Shapes Our Lives. Simon \& Schuster, New York, NY.

Li, Xinxin, Lorin M. Hitt. 2008. Self selection and information role of online product reviews. Information Systems Research 19(4) 456-474.

Martin, Matt. 2010. Ea to release paid dlc before boxed games. GameIndustry International Retreived from http://www.gamesindustry.biz. 
Mathios, A. 2000. The impact of mandatory disclosure regulations on health choices: An analysis of the salad dressing market. Journal of Law and Economics 43(2) 651-678.

Matthews, Steven, Andrew Postlewaite. 1985. Quality testing and disclosure. Rand Journal of Economics 16(3) $328-340$.

Milgrom, P. 1981. Good news and bad news: Representation theorems and applications. Bell Journal of Economics 12(2) 380-391.

Milgrom, Paul, John Roberts. 1986a. Price and advertising as signals of product quality. Journal of Political Economy 94(4) 796-821.

Milgrom, Paul, John Roberts. 1986b. Relying on the information of interested parties. Rand Journal of Economics 17(1) 18-32.

Montgomery, Alan L., Kartik Hosanagar, Ramayya Krishnan, Karen B. Clay. 2004. Designing a better shopbot. Management Science 50(2) 189-206.

Okuno-Fujiwara, Masahiro, Andrew Postlewaite, Kotaro Suzumura. 1990. Strategic information revelation. Review of Economic Studies 57(1) 25-47.

Salop, Steven C. 1979. Monopolistic competition with outside goods. The Bell Journal of Economics 10(1) $141-156$

Shavell, Steven. 1994. Acquisition and disclosure of information prior to sale. RAND Journal of Economics 25(1) 20-36.

Soberman, A. David. 2004. Additional learning and implications on the role of informative advertising. Management Science 50(12) 1744-1750.

Stivers, Andrew E. 2004. Unraveling of information: Competition and uncertainty. Topics in Theoretical Economics 4(1) Art. 9.

Sun, Monic Jiayin. 2011. Disclosing multiple product attributes. J. of Economics \& Mgmt Strategy 20(1) $195-224$.

Tirole, J. 1988. The Theory of Industrial Organization. MIT Press, Cambridge, Mass.

Verrecchia, Robert E. 1983. Discretionary disclosure. Journal of Accounting and Economics $5179-194$.

Wolinsky, Asher. 1983. Prices as signals of product quality. Review of Economic Studies 50(5) 647-658. 